Universidade de São Paulo

Faculdade de Filosofia, Ciências e Letras de Ribeirão Preto

Departamento de Psicologia e Educação

Programa de Pós-Graduação em Psicobiologia

\title{
Correlatos neuroquímicos em estruturas límbicas do comportamento exploratório de ratos submetidos à exposição única e repetida ao teste do \\ labirinto em cruz elevado.
}

Milene Cristina de Carvalho

Dissertação de Mestrado apresentada à Faculdade de Filosofia, Ciências e Letras de Ribeirão Preto-USP, como parte das exigências para obtenção do título de mestre em Ciências. Área de concentração: Psicobiologia. 
Universidade de São Paulo

Faculdade de Filosofia, Ciências e Letras de Ribeirão Preto

Departamento de Psicologia e Educação

Programa de Pós-Graduação em Psicobiologia

\title{
Correlatos neuroquímicos em estruturas límbicas do comportamento exploratório de ratos submetidos à exposição única e repetida ao teste do \\ labirinto em cruz elevado.
}

\author{
Milene Cristina de Carvalho
}

Dissertação de Mestrado apresentada à Faculdade de Filosofia, Ciências e Letras de Ribeirão Preto-USP, como parte das exigências para obtenção do título de mestre em Ciências. Área de concentração: Psicobiologia.

Orientador: Prof. Dr. Marcus Lira Brandão

Ribeirão Preto-SP 
AUTORIZO A REPRODUÇÃO E DIVULGAÇÃO TOTAL OU PARCIAL DESTE TRABALHO, POR QUALQUER MEIO CONVENCIONAL OU ELETRÔNICO, PARA FINS DE ESTUDO E PESQUISA, DESDE QUE CITADA A FONTE.

\section{FICHA CATALOGRÁFICA}

\section{Carvalho, Milene Cristina de}

Correlatos neuroquímicos em estruturas límbicas do comportamento exploratório de ratos submetidos à exposição única e repetida ao teste do labirinto em cruz elevado. Ribeirão Preto, 2005.

p. 87: il.; 30cm

Dissertação de Mestrado, apresentada à Faculdade de Filosofia, Ciências e Letras de Ribeirão Preto-USP - Área de Concentração: Psicobiologia.

Orientador: Brandão, Marcus Lira

1. one-trial tolerance. 2. Labirinto em Cruz Elevado. 3. Cromatografia Líquida de Alta Pressão. 4. Córtex pré-frontal. 5. Amígdala. 6. Hipocampo. 7. Núcleo accumbens. 
Dedico este trabalho

Aos meus amados pais Railda e Oswaldo, que sempre me incentivaram, em todos momentos da minha vida, a alcançar todos os objetivos traçados, independente do grau de dificuldade.

Ao meu querido irmão Franco, por sempre me transmitir serenidade e maturidade.

Ao meu sobrinho Pedro Eduardo, que trouxe muito mais alegria à minha vida.

Ao Fábio, que com muito amor e amizade, soube compreender meus momentos de insegurança. 


\section{AGRADECIMENTOS}

Ao Prof. Dr. Marcus Lira Brandão, pelo seu exemplo de dedicação à carreira científica e, pela oportunidade de conhecer e fazer pesquisa. À você, meus sinceros agradecimentos.

Ao Prof. Dr. Rodolfo Silveira, por me aceitar como estagiária e, iniciar meus conhecimentos em Cromatografia Líquida de Alta Pressão.

À Profa. Dra. Maria Angélica Souza e Silva, pela atenção e ensinamentos, que mesmo à distância, ajudaram-me na completa realização deste trabalho.

À Profa. Dra. Milena de Barros Viana e Prof. Dr. Cláudio da Cunha pela leitura prévia e, pelas sugestões que enriqueceram meu trabalho.

À Denise, Sônia e Maria Inês, pelos favores prestados na secretaria.

À Renata Vicentini, pelos auxílios administrativos prestados.

Ao Prof. Milton Camplesi Jr., pela amizade, paciência e dedicação ao passar todo seu conhecimento técnico sobre Cromatografia Líquida de Alta Pressão.

Ao Carlos Augusto dos Santos Pinto, pelo auxílio técnico.

À Cidinha e Sueli, pela amizade e por sempre manter a limpeza do laboratório.

À Daniele Aguiar, pelo companheirismo do último ano e pela amizade.

À Júlia, pela amizade, alegria e espontaneidade de viver... Muito obrigada!

A Profa. Dra. Sueli Masson, pelo grande auxílio experimental.

Ao Prof. Dr. Manoel Jorge do Espírito Santo, pelos ensinamentos em estatística.

Ao Prof. Carlos Eduardo Antunes de Macedo, pelo auxílio na elaboração gráfica.

Aos amigos e companheiros de laboratório Karina, Amanda, Lucas, Raquel, Adriano, Cristina, Caio, Juliana, Fernanda Tomazini, Fernanda Reis, Cecília, Vanessa, Marcos e Luciana.

Aos amigos do Departamento de Psicobiologia.

À todos que direta e indiretamente contribuíram para a realização deste trabalho.

À CAPES pelo apoio financeiro. 
"O valor das coisas não está no tempo que elas duram, mas na intensidade com que acontecem.

Por isso, existem momentos inesquecíveis, coisas inexplicáveis e pessoas incomparáveis."

Fernando Pessoa 


\section{RESUMO}

O efeito ansiolítico dos benzodiazepínicos (BZDs) é reduzido depois da primeira exposição ao labirinto em cruz elevado (LCE). Várias hipóteses tem sido formuladas para explicar este fenômeno chamado one-trial tolerance (OTT), entretanto, nenhuma delas é conclusiva. No presente estudo, examinamos este fenômeno através da análise etofarmacológica de ratos submetidos ao LCE em duas sessões (T1 e T2), e do conteúdo de monoaminas presentes no córtex pré-frontal, amígdala, hipocampo e núcleo accumbens através da técnica de Cromatografia Líquida de Alta Pressão. Ratos machos Wistar foram tratados com salina ou midazolam (0,5 mg/Kg, i.p.) antes de T1 e T2 e imediatamente depois, seus encéfalos foram dissecados e as estruturas analisadas. Como controle à análise neuroquímica foram incluídos animais tratados com salina e não expostos ao LCE. A administração de midazolam antes de T1 promoveu efeito ansiolítico, aumentando a exploração dos braços abertos, porcentagem de entradas e tempo de permanência nos mesmos. Em T2 foi observado redução da exploração dos braços abertos em relação a T1. Esses resultados sugerem que há uma mudança no estado emocional do animal em T2, que é resistente a ação ansiolítica dos BZDs. Com relação aos resultados dos estudos neuroquímicos, foi observado redução dos conteúdos de serotonina (5HT) e noradrenalina (NA) no córtex pré-frontal, na amígdala, no hipocampo e no núcleo accumbens depois de T1 e T2. Houve também, redução do conteúdo de dopamina (DA) na amígdala depois de ambas sessões. Não ocorreram mudanças nas taxas de renovação dessas monoaminas em nenhuma das estruturas analisadas. Através desses resultados, pode-se inferir que a estimulação aversiva do LCE causa alterações na neurotransmissão monoaminérgica da amígdala, como também das outras estruturas límbicas estudadas neste trabalho. Essas alterações neuroquímicas depois da primeira exposição ao LCE, devem representar alterações adaptativas na neurotransmissão do sistema límbico que podem estar associadas ao fenômeno da OTT. 


\begin{abstract}
Numerous reports have demonstrated that a single exposure to a variety of stressful experiences enhances fearful reactions when behavior is subsequently tested in current animal models of anxiety. Until now, no study has examined the neurochemical changes during the test and retest sessions of freely-behaving rats in the elevated plus-maze (EPM), one of the most traditional tests of anxiety. This work is a new approach looking at the changes in dopamine (DA), serotonin (5-HT) and noradrenaline (NA) levels in the prefrontal cortex, amygdala, hippocampus and nucleus accumbens during one-trial learning development. We used high pressure liquid chromatography to assess the concentrations of these neurotransmitters and their metabolites in animals injected with saline or midazolam upon single or double exposure to the EPM. For the biochemical analysis an extra control group treated with saline and not exposed to EPM was added. The data showed that stressful stimuli present in the maze were able to elicit one-trial learning to midazolam on re-exposure. Significant decreases in 5-HT and NA contents in the prefrontal cortex, amygdala, hippocampus and nucleus accumbens occurred in saline and midazolam injected animals submitted to the first and second trials. Significant decreases in DA content were also observed in the amygdala after both trials. There was no change in the turnover of these monoamines in any structure studied. It is suggested that aversive stimuli inherent to the EPM cause primary changes in the neurochemical mechanisms of the amygdala and also influence the activity of monoaminergic neurotransmission in the prefrontal cortex, hippocampus and nucleus accumbens. The observed reduction in monoaminergic transmission in limbic structures after the first stressful experience in the EPM seems to represent adaptive changes and may be associated to the phenomenon of "one-trial tolerance".
\end{abstract}




\section{LISTA DE ABREVIATURAS}

5-HIAA: Ácido 5-hidroxindolacético

5-HT: Serotonina

ACN: Acetonitrilo

AM: Amígdala

ATV: Área tegmental ventral

BZDs: Benzodiazepínicos

CPfr: Córtex pré-frontal

DA: Dopamina

DHBA: 3,4-Dihidroxibenzilamina hidrobrometo

DOPAC: 3,4-Dihidroxifenilacetico

EDTA: Ácido acético Etilenidiaminetetra

GABA: Ácido gama-aminobutírico

HP: Hipocampo

HPLC: Cromatografia Líquida de Alta Pressão
HVA: 3-Hydroxytryramine

i.p.: Intraperitonialmente

LCE: Labirinto em Cruz Elevado

M: Midazolam

MHPG: 3-metoxi-4-hidroxi-fenilglicol

NA: Noradrenalina

NAc: Núcleo accumbens

OTT: one-trial tolerance

PCA: Ácido Perclórico Aquoso 0,75 N

S: Salina

T1: Primeira sessão

T2: Segunda sessão

THF: Tetrahidrofurano

TTO: Tratamento 


\section{SUMÁRIO}

\begin{tabular}{|c|c|}
\hline Introdução & 11 \\
\hline Medo e Ansiedade & 12 \\
\hline Modelos animais de ansiedade & 13 \\
\hline Labirinto em cruz elevado & 14 \\
\hline LCE e tolerância aos benzodiazepínicos & 15 \\
\hline Abordagem neuroquímica & 17 \\
\hline Córtex pré-frontal & 18 \\
\hline Amígdala & 19 \\
\hline Hipocampo & 21 \\
\hline Núcleo accumbens & 22 \\
\hline Objetivos & 24 \\
\hline Material e Métodos & 26 \\
\hline Animais & 27 \\
\hline Droga & 27 \\
\hline Labirinto em cruz elevado & 27 \\
\hline Análise comportamental tradicional & 28 \\
\hline Freqüência de entradas & 28 \\
\hline Porcentagem de entradas nos braços abertos & 28 \\
\hline Porcentagem de tempo nos braços abertos & 28 \\
\hline Análise por categoria comportamental & 29 \\
\hline Neuroquímica & 30 \\
\hline Cromatografia Líquida de Alta Pressão & 30 \\
\hline Preparo das soluções padrão & 31 \\
\hline Preparo de PCA com DHBA para amostras & 32 \\
\hline Procedimento & 33 \\
\hline Análise "post-mortem" & 34 \\
\hline Análise estatística & 35 \\
\hline Resultados & 36 \\
\hline Análise comportamental tradicional & 37 \\
\hline Análise por categoria comportamental & 39 \\
\hline
\end{tabular}


$\begin{array}{ll}\text { Análise neuroquímica } & 42\end{array}$

Córtex pré-frontal 42

Amígdala 45

$\begin{array}{ll}\text { Hipocampo } & 48\end{array}$

Núcleo accumbens

Discussão $\quad 54$

\begin{tabular}{lr}
\hline Referências Bibliográficas & 65 \\
\hline
\end{tabular}

\begin{tabular}{lr}
\hline Apêndice & 79
\end{tabular}




\section{Introdução}




\section{Medo e Ansiedade}

Experiências emocionais têm um importante papel funcional a nível evolucionário em relação a comportamentos de defesa em situações de ameaça. Uma ameaça pode estar representada por estímulos inatos, ou ainda por estímulos condicionados. O estado de medo gerado pode desencadear comportamentos de luta e fuga (CRUZ; FREI; GRAEFF, 1994).

As raízes biológicas da ansiedade estão intimamente relacionadas com as reações de defesa dos animais, que ocorrem quando expostos a situações de perigo geralmente encontradas no ambiente em que vivem. Por este motivo, a ansiedade está intimamente relacionada ao medo, uma vez que tanto um quanto o outro é experienciado como algo desagradável ou ameaçador (NUTT, 1991). Deste modo, o medo e a ansiedade ocorrem em situações em que o mesmo comportamento é simultaneamente recompensado e punido, ou em situações novas ou desconhecidas, inibindo o comportamento exploratório, motivado pela curiosidade (GRAEFF, 1989).

De modo geral, a ansiedade pode ser definida como um estado emocional, de significado adaptativo e evolutivo, vivenciado subjetivamente como não prazeroso e ameaçador (GRAEFF, 1997). Suas manifestações incluem mudanças no humor e cognição, geralmente acompanhadas por alterações comportamentais e fisiológicas induzidas pela expectativa de perigo, dor ou necessidade de um esforço especial (NUTT, 1990; DRACTU; LADER, 1993).

Admite-se que certo estado de ansiedade seja motivador ao desempenho de tarefas motoras e cognitivas, que nos impulsionam na realização de mudanças e na busca de novas soluções para os problemas que enfrentamos cotidianamente. Essa emoção, contudo, passa a ser considerada patológica quando provoca respostas exacerbadas e irracionais, interferindo em nossas habilidades e impossibilitando-nos de agir normalmente. Segundo Blanchard e 
Blanchard (1987, 1988), um conceito importante para se diferenciar medo e ansiedade é a distância defensiva, pois diferentes tipos de comportamentos são observados em diferentes distâncias do predador. Se o mesmo estiver próximo surgem respostas relacionadas ao medo e se estiver distante surgem comportamentos relacionados à ansiedade. Vale ressaltar que é difícil estabelecer uma fronteira entre níveis normais e patológicos de ansiedade (PRATT, 1992; DRACTU; LADER, 1993; SANDFORD; ARGYROPOULOS; NUTT, 2000).

Segundo Mongeau, Blier e Montigny (1997), a depressão pode ocorrer secundariamente à ansiedade. Deste modo, quando a ansiedade ou condições aversivas não é resolvida, a ineficiência de mecanismos adaptativos de defesa pode desencadear a depressão.

\section{Modelos animais de ansiedade}

Com a utilização de modelos animais de ansiedade é possível reproduzir em laboratório aspectos da sintomatologia, etiologia, ou de possíveis tratamentos para a ansiedade, bem como estudar os mecanismos pelos quais estes compostos produzem seus efeitos (TREIT, 1985; FILE,1992).

Os modelos animais de ansiedade são divididos em dois grupos principais: modelos baseados em aprendizagem associativa e modelos baseados em medos inatos ou etologicamente fundamentados.

Muitos modelos animais de ansiedade envolvem processos de aprendizagem associativa baseados no condicionamento clássico e/ ou operante. No condicionamento clássico, estímulos neutros (condicionados), como sons de baixa intensidade e luzes, após o pareamento sucessivo com estímulos aversivos incondicionados, como choques elétricos e sons intensos podem, isoladamente, desencadear respostas de medo/ ansiedade (resposta condicionada). Neste sentido, esses estímulos neutros passariam a desencadear as respostas de 
medo/ ansiedade em decorrência de anteciparem para o animal a apresentação de um estímulo aversivo. No condicionamento operante, os animais aprendem determinadas estratégias para diminuir ou suprimir as conseqüências negativas associadas com a apresentação de estímulos aversivos. Quando as respostas dos animais são seguidas de apresentação do estímulo aversivo ocorre uma diminuição da expressão deste comportamento no futuro. Esta situação caracteriza a punição. Entre os modelos baseados em aprendizagem associativa estão a resposta emocional condicionada, resposta de sobressalto intensificada pelo medo, o teste de conflito do beber punido e punição de pressão à barra (GELLER; SEIFTER, 1960; VOGEL; BEER; CLODY, 1971).

Os modelos etologicamente fundamentados usam estímulos que desencadeiam respostas incondicionadas de medo em diferentes espécies animais frente a situações e/ ou estímulos naturalmente aversivos. Esses modelos oferecem várias vantagens sobre os modelos de punição, por não empregarem estímulos nocivos, como choques elétricos, privação de água ou de alimentos, por não requisitarem o treino ou a modelagem do comportamento do animal e por apresentarem baixo custo operacional (PELOW ET AL., 1985; LISTER, 1990). Entre os modelos etologicamente fundamentados estão a transição claro-escuro, a interação social, a interação presa - predador e o LCE.

\section{Labirinto em cruz elevado}

Este modelo é amplamente baseado na aversão natural de ratos e camundongos ao espaço aberto (TREIT; MENARD; ROYAN, 1993). O LCE origina-se do trabalho original de Montgomery (1955). Este autor utilizou um labirinto elevado em Y, com dois braços fechados e um aberto, no qual os ratos preferiam sistematicamente os braços fechados ao aberto. Em vista disso, sugeriu que a exposição a estímulos novos poderia provocar tanto um impulso à 
exploração quanto um estado de medo, gerando conflito. Na versão atual, o LCE é composto por dois braços fechados com paredes laterais e dois abertos, perpendiculares entre si e elevados em relação ao solo. O LCE induz a um conflito entre a tendência de exploração e o medo de altura e de espaço aberto. Assim, animais colocados neste teste têm tendência a evitar os braços abertos, permanecendo nos fechados.

Drogas que diminuem o medo/ ansiedade aumentam a freqüência de entradas e o tempo de permanência nos braços abertos do labirinto. Deste modo, drogas ansiolíticas aumentam o número de entradas e o tempo de permanência nos braços abertos, sendo que drogas ansiogênicas produzem efeito contrário (MORRISON; STEPHENSON, 1970). Geralmente estes efeitos são expressos através de índices correlacionados negativamente com a ansiedade, tais como a porcentagem das entradas ou o tempo despendido nos braços abertos em relação ao número total de entradas nos quatro braços ou o tempo total do teste que, em geral, é estabelecido em cinco minutos.

\section{LCE e tolerância aos benzodiazepínicos}

O LCE tem sido amplamente validado usando critérios comportamental, fisiológico e farmacológico (LISTER, 1990; PELLOW et al., 1985). Contudo, este modelo de labirinto tem uma característica intrigante em relação aos efeitos dos benzodiazepínicos: o fenômeno da OTT. De fato, há uma marcante atenuação ou abolição do efeito ansiolítico de BZDs por uma simples e prévia experiência no labirinto (LISTER, 1987; FILE, 1990; RODGERS; LEE; SHEPHERD, 1992; GONZALES; FILE, 1997; RODGERS; SHEPHERD, 1993).

O fenômeno da OTT foi primeiramente descrito por Lister (1987), e não é dependente do tratamento antes da primeira sessão, do intervalo entre as sessões e nem do material que o labirinto é construído, porém, parece ser controlado por uma aprendizagem na primeira sessão 
que é associada com a experiência nos braços abertos (FILE; MABBUTT, P; HITCHCOTT, 1990).

Existem vários estudos pré-clínicos que investigam a ocorrência de tolerância ao efeito ansiolítico de drogas, em especial com alprazolam, clordiazepóxido, diazepam, lorazepam, midazolam, nitrazepam, oxazepam e triazolam. Pode-se notar que a maioria deles relata o desenvolvimento de tolerância não apenas aos BZDs, mas também para outras drogas que facilitam a neurotransmissão via receptor $\mathrm{GABA}_{\mathrm{A}}$. Neste contexto, vários fatores, tais como tempo de meia vida prolongada, doses altas e administração contínua, parecem aumentar a incidência de tolerância ao efeito ansiolítico de drogas (HUTCHINSON; SMITH; DARLINGTON, 1996).

Tolerância é definida como uma redução nos efeitos de uma droga ao longo da exposição repetida a uma determinada dose, ou a necessidade de aumentá-la para obter o mesmo efeito (MILLER; GOLD, 1990; RALL, 1991).

O desenvolvimento de tolerância também parece envolver aspectos de aprendizagem (GOUDIE, 1990; KALANT, 1998; SIEGEL et al., 2000). Neste sentido, a contribuição da aprendizagem e a importância do contexto no qual a droga é administrada para a tolerância estão incorporados em análises que enfatizam os princípios do condicionamento clássico. Por meio deste condicionamento, pistas ambientais específicas que estão presentes no momento da administração da droga tornam-se associadas aos efeitos da droga (LÊ; POULOS; CAPPEL, 1979; SIEGEL, 1987). Como resultado, o contexto, por si só, induziria respostas compensatórias que minimizariam/ neutralizariam o desequilíbrio na homeostase produzido pela droga (SIEGEL; LARSON, 1996; WOODS; RAMSAY, 2000). Se considerarmos que a aprendizagem influencia o desenvolvimento de tolerância farmacológica, não é surpresa que esta última deixe de se manifestar quando intervirmos com processos de aprendizagem. 
O fenômeno da OTT parece ser altamente dependente da aprendizagem aversiva da primeira exposição ao labirinto. Tal situação foi associada ao fato de que, em uma exposição inicial, o animal experimenta estados concorrentes de ansiedade e medo no LCE. Como conseqüência, a predominância do medo na reexposição é responsável pela ineficácia dos BZDs nas alterações das medidas do teste relacionadas à ansiedade (CRUZ-MORALES; SANTOS; BRANDÃO, 2002).

Várias hipóteses foram propostas para explicar o fenômeno da OTT, dentre as quais podemos destacar aquela que atribuiu a uma mudança qualitativa na natureza do estado emocional do animal gerado nas exposições ao LCE, provavelmente com aquisição de fobia (FILE; MABBUTT; HITCHCOTT, 1990; FILE; ZANGROSSI, 1993; RODGERS; SHEPHERD, 1993; HOLMES; RODGERS, 1998). De acordo com esta hipótese, a resposta de medo incondicionado evocada na primeira exposição se transformaria em uma resposta de esquiva aprendida durante a segunda exposição, contra a qual os BZDs seriam ineficazes (FILE, 1993; FILE et al., 1993; BERTOGLIO; CAROBREZ, 2002c; CRUZ-MORALES; SANTOS; BRANDÃO, 2002).

\section{Abordagem Neuroquímica}

O fenômeno da OTT está bem caracterizado comportamentalmente por meio de inúmeros trabalhos que relatam a ineficácia de diversos BZDs em promover efeitos “ansiolíticos” na segunda sessão do teste do LCE. Entretanto, muito pouco se conhece da neurobiologia deste fenômeno e menos, ainda, das alterações neuroquímicas subjacentes ao estabelecimento desta tolerância. Este trabalho é uma tentativa de prestar uma contribuição a esta linha de investigação através da análise dos níveis de 5-HT, DA e seus metabólitos e, da NA em algumas estruturas envolvidas na organização do comportamento emocional (sistema 
límbico), tais como o córtex pré-frontal, amígdala, hipocampo e núcleo accumbens, em ratos submetidos a uma única exposição e a exposições repetidas ao LCE. Estas estruturas possuem importante interação anatômica e estão envolvidas em modalidades funcionais interdependentes que coordenam o comportamento emocional e cognitivo.

A seguir é feita uma descrição sucinta do papel destas estruturas e de mecanismos serotoninérgicos, dopaminérgicos e noradrenérgicos na neurobiologia do medo/ ansiedade:

\section{Córtex pré-frontal}

O córtex pré-frontal é uma estrutura crucial no estabelecimento de processos cognitivos e de decisões, determinados com base no valor do estímulo (GOLDMAN-RAKIC, 1995). O córtex pré-frontal é também ativado em respostas a estímulos ameaçadores (BLISS; AILION; ZWANZIGER, 1968; THIERRY et al., 1976; WEISS et al., 1981; DEUTCH; ROTH, 1990; TANAKA et al., 1990; INOUE; KOYAMA; YAMASHITA, 1993). A ativação metabólica do sistema dopaminérgico no córtex pré-frontal de ratos, em resposta a estímulos aversivos, é um dos correlatos neuroquímicos do estresse mais estudados (DEUTCH; ROTH, 1990). Os corpos celulares dopaminérgicos estão localizados na área tegmental ventral (ATV) no núcleo $\mathrm{A}_{10}$, de onde partem projeções para o córtex (GOLDMAN-RAKIC et al., 1989; VINCENT; KHAN; BENES, 1993). O aumento de DA no córtex pré-frontal é produzido por uma variedade de estímulos aversivos incondicionados (THIERRY et al., 1976; FADDA et al., 1978; REINHARD; BANNON; ROTH, 1982; CLAUSTRE et al., 1986; ROTH et al., 1988) e, estresse condicionado e incondicionado (GOLDSTEIN et al., 1994, 1996; KANEYUKI et al., 1991).

A exposição ao estresse também causa um aumento do metabolismo noradrenérgico em várias regiões cerebrais (MAAS; DEKIRMENJIAN; FAWCETT, 1971; SWEENEY; 
MAAS; HENINGER, 1978; GLAVIN, 1985; DUNN, 1988; TANAKA et al., 1990). Estes resultados são consistentes com o trabalho de Jacobs et al. (1991), na qual a indução do estresse causou aumento da atividade eletrofisiológica nos neurônios do locus coeruleus. Investigações anteriores (BLISS, 1968) mostraram que a exposição de ratos a estímulos estressantes incontroláveis, como choque nas patas, resultou na diminuição dos níveis corticais de NA concomitantemente com o aumento dos níveis de seus metabólitos, enquanto que o mesmo estímulo estressante acelerou o metabolismo de DA e 5-HT sem alterar o nível absoluto dessas aminas. Recentes estudos, utilizando microdiálise, têm mostrado que a liberação de NA no córtex pré-frontal é aumentada por estresse incondicionado (CENCI et al., 1992; NAKANE; SHIMIZU; HORI, 1994; FINLAY; ZIGMOND; ABERCROMBIE, 1995).

Tem sido relatado que em situações estressantes ocorre aumento no metabolismo cerebral de 5-HT (THIERRY; FEKETE; GLOWIINSKI, 1968; DUNN, 1988), embora esses achados não sejam relatados em todos estudos (KANEYUKI et al., 1991). Ao lado disso, um aumento dos níveis de 5-HIAA em ratos reexpostos a um contexto ou a um tom previamente pareado com choque nas patas foi consistentemente demonstrado (INOUE; KOYAMA; YAMASHITA, 1993; GOLDSTEIN et al., 1994). Esta condição, portanto, pode ser decorrente de maior atividade neuronial serotoninérgica com conseqüente redução da 5-HT.

\section{Amígdala}

Há extensa e crescente literatura implicando a amígdala na coordenação de respostas comportamentais, neurohumorais e neuroquímicas das emoções (LEDOUX, 1992; DAVIS et al., 1994). Estudos neuroanatômicos têm demonstrado que do núcleo central da amígdala partem projeções para a ATV (área que inerva o córtex pré-frontal), locus coeruleus e núcleos da rafe (GONZALES; CHESSELET, 1990; WALLACE; MAGNUSON; GRAY, 1992). 
Estudos eletrofisiológicos têm demonstrado que a grande maioria de células dopaminérgicas da ATV responde a estimulação elétrica da amígdala (MAEDA; MOGENSON, 1981). Ao lado disso, a amigdalectomia bloqueia o aumento de DA no córtex pré-frontal em situações de estresse, o que sugere o envolvimento da amígdala no controle aferente de respostas emocionais mediadas pelo sistema mesocortical dopaminérgico ao estresse psicológico (DAVIS et al., 1994; GOLDSTEIN et al., 1996). Sem dúvida, a amígdala influencia o metabolismo dopaminérgico no córtex pré-frontal. Esta hipótese é baseada na presença de conexões recíprocas entre o núcleo basolateral e o córtex pré-frontal (KRETTEK; PRICE, 1977; MCDONALD, 1991).

O sistema noradrenérgico também recebe projeções funcionais regulatórias da amígdala durante o estresse. De fato, a amigdalectomia impede a ativação do metabolismo noradrenérgico durante o estresse. Sabe-se que o núcleo central da amígdala envia projeções diretas e indiretas para o locus coeruleus, origem dos neurônios noradrenérgicos que inervam o córtex. Estudos imunohístoquímicos também têm demonstrado que neurônios positivos para tirosina hidroxilase - enzima envolvida na síntese de NA - no locus coeruleus recebem aferências do núcleo central da amígdala (WALLACE; MAGNUSON; GRAY, 1992).

A demonstração de que a amigdalectomia bloqueia a ativação do sistema serotoninérgico no córtex pré-frontal, após a reexposição ao estímulo pareado previamente com choque nas patas, sugere que a amígdala também fornece aferências regulatórias para o sistema serotoninérgico durante o estresse. O núcleo central da amígdala envia projeções para o núcleo dorsal da rafe (WALLACE; MAGNUSON; GRAY, 1992). Além disso, neurônios serotoninérgicos tanto do núcleo dorsal quanto do mediano da rafe projetam-se de volta para o córtex pré-frontal (AZMITIA; SEGAL, 1978; MOORE; HALARIS; JONES, 1978). 


\section{Hipocampo}

O hipocampo tem importantes conexões com o tálamo, hipotálamo e córtex entorrinal e, compõe o Circuito de Papez. Estas conexões lhe permitem atuar como conferidor das informações sensoriais provenientes do córtex entorrinal, e confrontá-las com as predições geradas ao nível do circuito de Papez que, por sua vez, integra informações de outras partes do cérebro, incluindo o córtex pré-frontal. Quando há incompatibilidade entre os eventos ambientais e o que está armazenado, o hipocampo passa a funcionar como modalidade controle, que gera inibição comportamental, acompanhada por aumento de atenção ao meio e do aumento da vigilância aos estímulos potencialmente perigosos (MCNAUGHTON; GRAY, 2000; BRANDÃO, 2001). Esta função hipocampal é de grande importância em situações em que se estabelece o conflito entre evitar o estímulo potencialmente perigoso e aproximar-se dele (MCNAUGHTON; GRAY, 2000). Esta situação de conflito é bastante evidente na primeira exposição ao LCE, mas reduz-se significativamente no reteste, quando é substituída por estados emocionais de natureza diferente (CRUZ-MORALES; SANTOS; BRANDÃO, 2002).

Os mecanismos serotoninérgicos do hipocampo são cruciais no processo de informação aversiva (GOLDSTEIN et al., 1996; GRAEFF; DEAKIN, 1991; DEAKIN; GRAEFF; GUIMARAES, 1992). O efeito amnésico causado por lesões hipocampais é bem documentado, levando a numerosas teorias de função hipocampal sobre memória, contudo, esses danos podem resultar em desinibição comportamental e redução da ansiedade. Um número crescente de estudos sugere que esses efeitos comportamentais diversificados devem ser associados a diferentes subregiões hipocampais. O hipocampo dorsal tem papel preferencial em certas formas de aprendizagem e memória, notavelmente aprendizagem 
espacial, enquanto que o hipocampo ventral tem papel preferencial em processos cerebrais associado à ansiedade (BANNERMAN et al., 2004).

\section{Núcleo accumbens}

O núcleo accumbens é uma estrutura onde estímulos com valores afetivos e emocionais interagem com áreas motoras (MOGENSON; JONES; YIM, 1980; PENNARTZ; GROENEWEGEN; LOPEZ DA SILVA, 1994). Como o LCE avalia a reatividade emocional dos animais através da combinação da atividade motora com o medo de altura e espaços abertos, incluiu-se o núcleo accumbens na análise neuroquímica. O núcleo accumbens é considerado uma importante área de produção de respostas emocionais, contudo, mudanças no seu conteúdo monoaminérgico poderiam implicar em várias desordens cerebrais, incluindo a ansiedade (SESACK; PICKEL, 1992).

O núcleo accumbens funciona como uma interface entre os sistemas motivacional e motor de modo a servir de canal por onde o estímulo com valor afetivo e emocional acessa as vias efetoras - motoras (MOGENSON; JONES; YIM, 1980; PENNARTZ; GROENEWEGEN; LOPEZ DA SILVA, 1994). Como componentes do sistema límbico, a amígdala, o hipocampo, o núcleo accumbens e o córtex pré-frontal estão envolvidos em

modalidades funcionais interdependentes que coordenam o comportamento emocional e cognitivo (ROTH et al., 1988; GOLDSTEIN et al., 1996).

Sabe-se que a exposição a um estresse moderado ativa o sistema dopaminérgico no córtex pré-frontal enquanto não afeta o metabolismo dopaminérgico no estriado. Por outro lado, a exposição a um estresse mais intenso resulta em um recrutamento do sistema dopaminérgico mesolímbico que inerva o núcleo accumbens (ROTH et al., 1988; GOLDSTEIN et al., 1996). O córtex pré-frontal, amígdala e o núcleo accumbens estão, 
portanto, conectados anatômica e funcionalmente. A regulação cognitiva que o córtex préfrontal exerce sobre a reatividade emocional organizada na amígdala e núcleo accumbens é uma evidência importante nesse sentido (GOLDSTEIN et al., 1996). 
Objetivos = 
Investigar a correlação entre comportamento e alterações neuroquímicas em estruturas límbicas na tolerância aos BZDs observada no LCE. Especificamente, serão estudadas as alterações no conteúdo de monoaminas (5-HT, DA e NA) e em seus metabólitos no córtex pré-frontal, na amígdala, no hipocampo e no núcleo accumbens, após o tratamento com salina e midazolam, em animais submetidos a uma ou duas sessões ao teste do LCE. Ratos não expostos ao LCE serão utilizados como controle. 
Material e Métodos

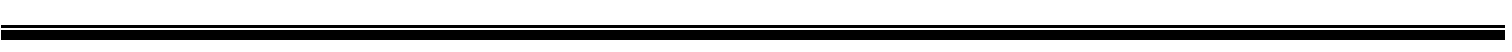




\section{Animais}

Foram utilizados ratos Wistar machos, adultos, ingênuos, pesando no início das sessões experimentais entre 280 e 320 gramas, provenientes do biotério central da Universidade de São Paulo, Campus de Ribeirão Preto. Os animais foram mantidos no biotério do laboratório de Neuropsicofarmacologia, do setor de Psicobiologia, por 48 h antes do início das sessões experimentais em caixas com maravalha em grupos de 5 animais por caixa. O biotério foi mantido com temperatura $\left(22 \pm 1^{\circ} \mathrm{C}\right.$ ) e iluminação (ciclo de $12 / 12 \mathrm{~h}$ ) controladas. Os animais receberam água e comida ad libitum.

\section{Droga}

A droga utilizada foi o maleato de midazolam (Roche) na dose de $0,5 \mathrm{mg} / \mathrm{Kg}$ diluída em salina ( $\mathrm{NaCl}-0,9 \%)$.

\section{Labirinto em Cruz Elevado}

O LCE consiste em um aparelho elevado $50 \mathrm{~cm}$ do solo, composto por dois braços abertos $(50 \times 10 \mathrm{~cm})$ dispostos perpendicularmente a dois braços fechados por paredes de madeira, desprovidos de teto (50 x 10 x $40 \mathrm{~cm}$ ), formando um ângulo de 90 graus. Ao redor dos braços abertos foram acopladas lâminas acrílicas, fazendo uma borda de $1 \mathrm{~cm}$ de altura. Os animais foram colocados no centro do labirinto $(10$ x $10 \mathrm{~cm})$ no início de cada sessão.

O LCE foi mantido no interior de uma sala iluminada artificialmente por luz branca (50 lux), onde havia uma câmara de vídeo que registrava os movimentos dos animais durante o tempo de experimento. A imagem gravada em fita de vídeo foi posteriormente analisada 
com o auxílio de um aparelho de vídeo-cassete acoplado a uma TV e um computador. A análise do comportamento do animal foi feita através de um programa de observação comportamental (OBSERVER, Noldus Inf. Co.; Wageningen, Netherlands).

\section{Análise Comportamental Tradicional}

\section{Freqüência de entradas}

O número de entradas foi obtido através da soma do número total de entradas nos braços abertos e o número total de entradas nos braços fechados do labirinto (PELLOW et al., 1985).

\section{Porcentagem de entradas nos braços abertos}

A porcentagem de entrada nos braços abertos foi obtida através da relação entre o número de entradas nos braços abertos do labirinto e o número total de entradas (braços abertos + fechados).

\section{Porcentagem de tempo nos braços abertos}

A porcentagem de tempo nos braços abertos foi obtida através da relação entre o tempo de permanência nos braços abertos do labirinto pelo tempo total do teste (5 minutos). 


\section{Análise por Categoria Comportamental}

O comportamento apresentado durante o teste foi analisado, considerando 9 categorias comportamentais: autolimpeza, levantamento, esticamento, espreitamento, esquadrinhamento, exploração da extremidade aberta, mergulho da cabeça, rastejamento e imobilidade (ANSELONI et al., 1995).

* Autolimpeza (grooming): seqüência de autolimpeza corporal começando pelo focinho, indo às orelhas e terminando pela limpeza do corpo inteiro;

* Esquadrinhamento (scanning): projeções da cabeça sobre as bordas de um braço, esquadrinhando em qualquer direção;

* Mergulho da cabeça (head-dipping): movimento exploratório de cabeça/ombros nas laterais do labirinto em direção ao precipício;

* Esticamento (streched attend posture): uma postura exploratória na qual o animal estica-se e se contrai à posição original, sem se locomover para frente;

* Rastejamento (flat back approach): locomoção exploratória onde o animal esticase totalmente e cuidadosamente move-se para frente;

* Levantamento (rearing): consiste na postura bípede do rato, apoiando-se com as patas posteriores no assoalho do labirinto, estando completamente ereto ou semiarqueado;

* Exploração da extremidade aberta (end-exploration): o animal alcança a extremidade do braço aberto e mergulha com a cabeça;

Espreitamento (peeping out): projeções da cabeça/ombros dos braços fechados para o centro, sendo que as quatro patas permanecem no braço fechado. 
* Imobilidade (Immobility): ausência de movimentos por um período maior do que 6 segundos em algum braço do labirinto.

\section{Neuroquímica}

O método utilizado para a separação e quantificação das monoaminas foi o de Cromatografia Líquida de Alta Pressão (HPLC) associado à detecção eletroquímica.

\section{Cromatografia Líquida de Alta Pressão}

Nesta análise foi utilizada uma coluna Hypurity Elite $C_{18} 5 \mu$, com dimensões 250 x 4,6 mm, um detector eletroquímico L - ECD - 6A, o módulo de comunicação CBM - 10A, um cromatógrafo LC - 10AD e um desgaseificador DGU - 14A (todos fabricados pela SHIMADZU, Japão). O fluxo da fase móvel foi de $1,2 \mathrm{ml} / \mathrm{min}$ e sua composição foi a seguinte (para um volume de 1 L): 150 mM de Ácido Cloroacético (SIGMA), 6 mM de Hidróxido de Sódio (MERCK), 1 L de água bidestilada, $\mathrm{pH}=3$ (para um valor de pH igual a 3 foi necessário utilizar os dois sais citados acima), 0,86 mM de Octylsulfate (SIGMA), 0,67 mM de EDTA (SIGMA), 3,5 \% de Acetonitrilo (MERCK) e 2,46 \% de Tetrahidrofurano (MERCK). A sensibilidade máxima do detector eletroquímico é de 2 nA e o potencial de oxidação do eletrodo de trabalho foi fixado a $850 \mathrm{mV}$ frente a um eletrodo de referência. 


\section{Preparo das soluções padrão}

A calibração do sistema de HPLC foi feita com duas soluções de concentrações distintas (1 e $5 \mathrm{ng} / 50 \mu \mathrm{L}$ ) de monoaminas e metabólitos: NA, DA, 5-HT, Ácido 5hidroxindolacético (5-HIAA), 3,4-Dihidroxifenilacetico (DOPAC) e 3-Hidroxitriramina (HVA) - (SIGMA) e também o padrão interno 3,4-Dihidroxibenzilamina hidrobrometo (DHBA) - (SIGMA). Essas soluções foram injetadas no sistema de HPLC seguindo a ordem de programação do Software (SHIMADZU-LC Workstation System) e em seguida foi feita a calibração baseada na análise de cada uma das soluções acima com o auxílio do Software. Após a calibração, uma amostra de solução padrão foi analisada para verificar se a calibração foi correta.

O preparo dos padrões, inclusive do padrão interno DHBA foi feito da seguinte forma: pesagem das substâncias em frascos de vidros separados para cada uma delas, totalmente limpos, identificados e envolvidos com papel alumínio. Foi acrescentado o Ácido Perclórico 0,2 M (PCA) e logo em seguida, a solução foi agitada num agitador magnético. A esta solução foi dado o nome de Solução A com a concentração de 0,5 mg/mL. Todas, imediatamente após o preparo, foram colocadas em gelo. Foram feitas alíquotas das Soluções A e estocadas, no máximo, por 30 dias num freezer com uma temperatura de $-70^{\circ} \mathrm{C}$.

A preparação do padrão normal, assim chamado por conter as concentrações iguais de monoaminas e do padrão interno, se iniciou pela pipetagem de $5 \mu \mathrm{L}$ de cada Solução A, inclusive a do padrão interno. O volume foi completado para $1000 \mu \mathrm{L}$ com PCA 0,2 M e logo em seguida, a solução foi agitada em um agitador magnético. Esta solução foi denominada Solução $\mathbf{B}_{1}$. A partir desta solução, foi feita a Solução $\mathbf{C}_{1}$ pela pipetagem de $50 \mu \mathrm{L}$ da 
Solução $\mathrm{B}_{1}$ e a adição de $1200 \mu \mathrm{L}$ de PCA 0,2 M que em seguida foi agitada em um agitador magnético.

A preparação do padrão diluído, assim chamado por conter concentrações diferentes de monoaminas do padrão interno, se iniciou pela pipetagem de $5 \mu \mathrm{L}$ de cada Solução A de monoaminas e $25 \mu \mathrm{L}$ de padrão interno DHBA. O volume da solução foi completado para $1000 \mu \mathrm{L}$ com PCA 0,2 M e logo em seguida foi agitada em um agitador magnético. Esta solução foi denominada Solução $\mathbf{B}_{2}$. A partir desta solução, foi feita a Solução $\mathbf{C}_{2}$ pela pipetagem de $10 \mu \mathrm{L}$ da Solução $\mathrm{B}_{2}$ e adição de $1240 \mu \mathrm{L}$ de PCA 0,2 M que em seguida foi agitada em um agitador magnético.

Todas as soluções, partindo-se da $B$, foram feitas diariamente. As Soluções $C_{1}$ e $C_{2}$ foram utilizadas para a calibração do sistema de HPLC.

\section{Preparo de PCA com DHBA para amostras}

A preparação desta solução consistiu na pipetagem de $10 \mu \mathrm{L}$ da Solução A de DHBA (0,5 mg/mL) e na elevação para o volume final de $50 \mathrm{~mL}$ com PCA 0,2 M. A concentração desta solução foi de 5 ng/ $50 \mu \mathrm{L}$. 


\section{Procedimento}

Os animais foram divididos nos seguintes grupos:

\begin{tabular}{|c|c|c|c|}
\hline Grupos & $\mathrm{N}$ & $1^{\circ}$ sessão (T1) & $2^{\circ}$ sessão (T2) - 24 hr após a $1^{\mathrm{a}}$ \\
\hline 1 & 8 & Salina (não exposto ao LCE) & - -------------- \\
\hline 2 & 8 & Midazolam (não exposto ao LCE) & - --------------- \\
\hline 3 & 8 & Salina & Salina \\
\hline 4 & 8 & Midazolam & Midazolam \\
\hline 5 & 8 & Salina & Salina \\
\hline 6 & 8 & Salina & Midazolam \\
\hline 9 & 8 & Midazolam & Midazolam \\
\hline
\end{tabular}

No estudo comportamental com o LCE, grupos independentes de animais receberam injeções de salina ou midazolam antes da (s) exposição (s) ao labirinto (grupos 3, 4, 5 e 6).

No estudo neuroquímico, um grupo controle adicional foi usado (grupo 1). Os animais deste grupo eram tratados com salina, mas não eram expostos ao LCE. Após 20 minutos na sala experimental, os animais eram sacrificados da mesma forma que os animais expostos ao LCE. Outros grupos (2, 6 e 7) também foram estudados. Como os resultados destes grupos não apresentaram subsídios importantes ao presente trabalho, eles não fazem parte do corpo desta dissertação, mas podem ser vistos no apêndice (tabelas 1, 2, 5, 6, 7, 8, 9 e 10).

Quinze minutos após a injeção intraperitonial (i.p.), o animal foi colocado na área central do labirinto com a cabeça direcionada para um dos braços fechados. Imediatamente após a primeira ou segunda exposição, os animais foram sacrificados para a análise bioquímica descrita a seguir. 


\section{Análise 'post-mortem'}

Cada animal foi anestesiado com gás carbônico $\left(\mathrm{CO}_{2}\right)$ durante 2 minutos, decapitado e seu encéfalo retirado. Foram feitas secções coronais e destas foram dissecados o córtex préfrontal, amígdala, hipocampo e núcleo accumbens. As secções foram feitas com o auxílio de uma matrix de metal com precisão de cortes de $1 \mathrm{~mm}$ e as dissecações foram feitas sobre uma placa de Petri mantida em gelo. As estruturas dissecadas foram pesadas em tubos Ependorffs devidamente identificados e preenchidos com $500 \mu \mathrm{L}$ de uma mistura de PCA 0,2 M e DHBA, sendo em seguida sonicadas por 20 segundos e centrifugadas a 15.000 rpm durante 20 minutos a $6^{\circ} \mathrm{C}$. O sobrenadante foi colocado em tubos Ependorffs identificados e guardados à $-70^{\circ} \mathrm{C}$ por um tempo máximo de 15 dias até serem analisados.

Amostras do sobrenadante foram injetadas em um sistema de HPLC com detecção eletroquímica. O conteúdo das monoaminas e de seus metabólitos foi expresso em ng/mg de tecido.

A razão 5-HIAA/5-HT foi usada como índice da atividade do sistema serotoninérgico e as razões DOPAC/DA e HVA/DA foram usados como índices da atividade do sistema dopaminérgico (KERDELHUE et al., 1989). Não foi possível avaliar o índice da atividade do sistema noradrenérgico devido a ausência de valores detectáveis do metabólito da NA, o 3metoxi-4-hidroxi-fenilglicol (MHPG). Como os resultados referentes à razão HVA/DA não apresentaram subsídios importantes ao presente trabalho, eles não fazem parte do corpo desta dissertação, mas podem ser vistos no apêndice (Tabelas 3 e 4). 


\section{Análise Estatística}

Os dados são apresentados como média + EPM. Para análise estatística dos dados comportamentais foi utilizado a ANOVA de duas vias, sendo o fator 1 , os tratamentos (midazolam e salina) e, o fator 2, a primeira (T1) e segunda (T2), sessões. Para avaliar as alterações no conteúdo de neurotransmissores em cada sessão, foi utilizada a ANOVA de uma via. Em caso de significância estatística do tratamento, realizou-se o teste post-hoc de Duncan. O nível de significância considerado foi de 5 \%. 
Resultados 


\section{Análise Comportamental Tradicional}

A figura 1 mostra a freqüência de entradas nos braços abertos e fechados e porcentagem de tempo de permanência e entradas nos braços abertos em relação aos braços fechados em T1 e T2. A ANOVA de duas vias mostrou que houve diferença estatisticamente significativa no fator sessões quanto à freqüência de entradas nos braços abertos $[\mathrm{F}(1,40)=$ 17,1; $\mathrm{p}<0,05$ ]. Foi observada uma tendência ao efeito estatisticamente significativo no fator tratamentos $\left[\mathrm{F}_{(1,40)}=3,29 ; \mathrm{p}=0,07\right]$, porém, nenhum efeito estatisticamente significativo foi observado na interação entre os tratamentos versus sessões na freqüência de entradas nos braços abertos $[\mathrm{F}(1,40)=1,18 ; \mathrm{p}>0,05]$. A análise post-hoc de Duncan indicou aumento em M1 em relação à S1 e, diminuição em S2 e M2 em relação aos seus grupos correspondentes em T1. Quanto à freqüência de entradas nos braços fechados, a ANOVA de duas vias mostrou que não houve diferença estatisticamente significativa no fator tratamentos $[\mathrm{F}(1,40)=0,30 ; \mathrm{p}>$ 0,05], no fator sessões [F $(1,40)=3,08 ; \mathrm{p}>0,05]$ e interação entre tratamentos versus sessões $[\mathrm{F}(1,40)=0 ; \mathrm{p}>0,05]$.

Quanto à porcentagem de tempo de permanência nos braços abertos, a ANOVA de duas vias mostrou que ocorreu diferença estatisticamente significativa nos fatores tratamentos $\left[F_{(1,40)}=4,33 ; p<0,05\right]$ e sessões $[F(1,40)=25,26 ; \mathrm{p}<0,05]$. Nenhum efeito estatisticamente significativo foi observado na interação entre os tratamentos versus sessões na porcentagem de tempo de permanência nos braços abertos $[\mathrm{F}(1,40)=2,32 ; \mathrm{p}>0,05]$. A análise post-hoc de Duncan indicou aumento no grupo M1 e, diminuição no grupo M2 em relação ao grupo S1 e, em S2 e M2, redução em relação aos seus grupos correspondentes em T1 em ambos os casos. Quanto à porcentagem de entradas nos braços abertos, a ANOVA de duas vias mostrou que houve diferença estatisticamente significativa no fator sessões $[F(1,40)=24,23$; p $<0,05]$.

Nenhum efeito estatisticamente significativo foi observado no fator tratamentos $[\mathrm{F}(1,40)=$ 
3,46; p > 0,05] e interação entre tratamentos versus sessões na porcentagem de entradas nos braços abertos $[\mathrm{F}(1,40)=1,14 ; \mathrm{p}>0,05]$. A análise post-hoc de Duncan indicou aumento no grupo M1 e, diminuição no grupo M2 em relação ao grupo S1 e, em S2 e M2, redução em relação aos seus grupos correspondentes em T1.
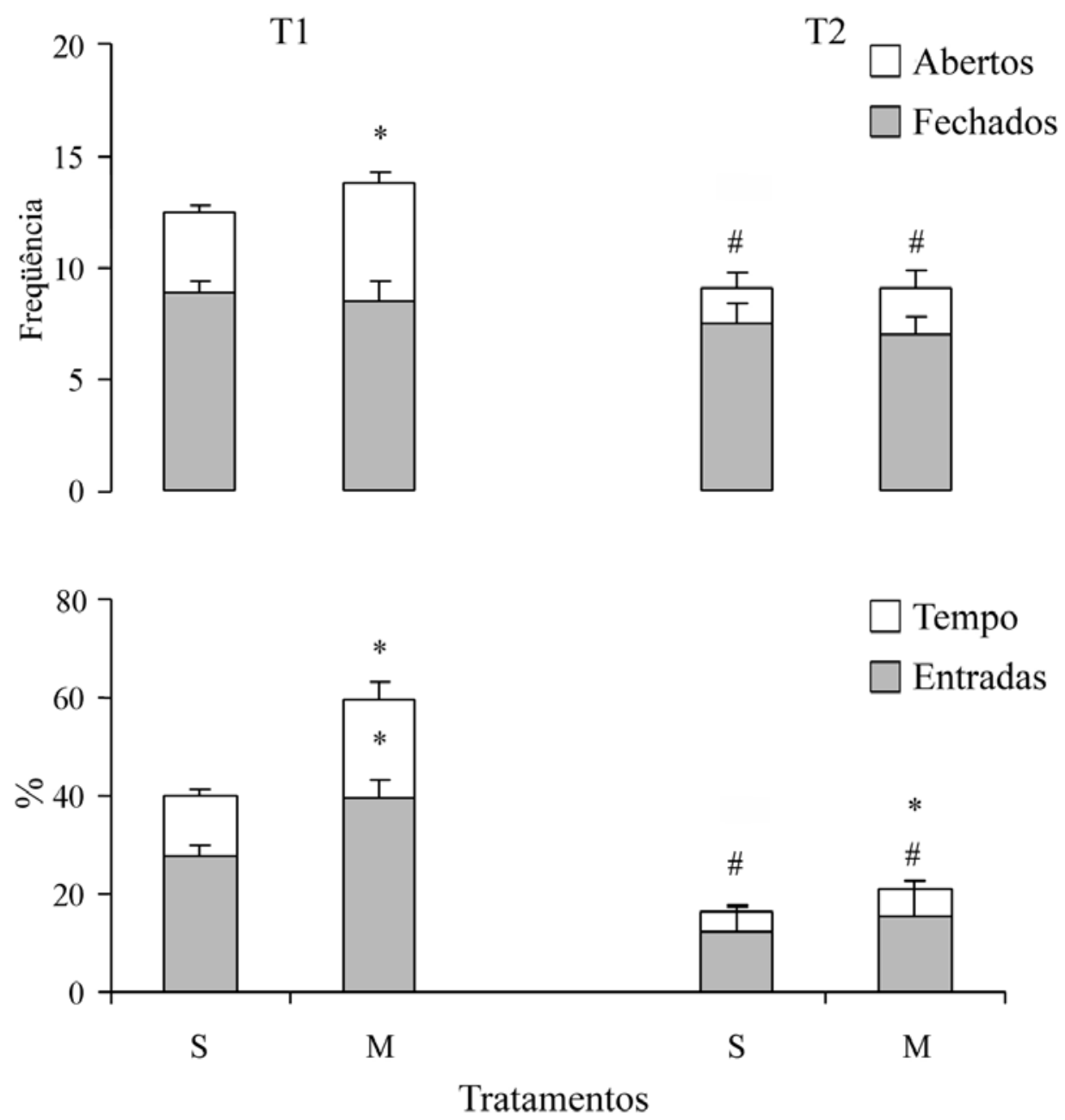

Figura 1: Efeitos do midazolam (0,5 mg/Kg, i.p.) sobre o comportamento exploratório de ratos submetidos à primeira (T1) e segunda (T2) sessões no LCE. Estão representadas as freqüências de entradas nos braços e a \% de entradas e de tempo de permanência nos braços abertos em relação ao total. Cada animal recebeu uma injeção 15 minutos antes de T1 e T2 com 24 horas de intervalo. As barras representam as médias + EPM. S: salina e M: midazolam. * $\mathrm{p}<0,05$ diferente do grupo S1; \# $\mathrm{p}$ $<0,05$ diferente do grupo correspondente em T1. ANOVA de duas vias seguida pelo teste post-hoc de Duncan. $\mathrm{N}=11$ para cada grupo. 


\section{Análise por Categoria Comportamental}

A figura 2 mostra a freqüência dos itens comportamentais em T1 e T2. Com relação à exploração da extremidade aberta, a ANOVA de duas vias mostrou que houve diferença estatisticamente significativa no fator sessões $[F(1,40)=10,6$; $p<0,05]$. Nenhuma diferença estatisticamente significativa foi observada no fator tratamentos $\left[F_{(1,40)}=2,65\right.$; p $\left.>0,05\right]$ e interação entre tratamentos versus sessões $[\mathrm{F}(1,40)=1,18 ; \mathrm{p}>0,05]$. A análise post-hoc de Duncan indicou que houve redução deste comportamento nos grupos M2 em relação ao grupo M1.

Quanto ao rastejamento, a ANOVA de duas vias mostrou que houve diferença estatisticamente significativa no fator sessões $[F(1,40)=9,66$; $p<0,05]$. Nenhuma diferença estatisticamente significativa foi observada no fator tratamentos $[F(1,40)=0,27$; p $>0,05]$ e interação entre tratamentos versus sessões $[\mathrm{F}(1,40)=0,12 ; \mathrm{p}>0,05]$. A análise post-hoc de Duncan indicou que houve redução deste comportamento no grupo S2 em relação aos grupos S1.

Com relação ao esticamento, a ANOVA de duas vias mostrou que houve diferença estatisticamente significativa no fator tratamentos $\left[F_{(1,40)}=4,21 ; p<0,05\right]$ e interação entre os tratamentos versus sessões [F $(1,40)=4,21 ; \mathrm{p}<0,05]$. Nenhuma diferença estatisticamente significativa foi observada no fator sessões $[\mathrm{F}(1,40)=1,97 ; \mathrm{p}>0,05]$. A análise post-hoc de Duncan indicou que houve aumento deste comportamento no grupo S2 em relação ao grupo S1.

Quanto ao mergulho da cabeça, a ANOVA de duas vias mostrou que houve diferença estatisticamente significativa no fator sessões $[F(1,40)=53,06 ; p<0,05]$. Nenhuma diferença estatisticamente significativa foi observada nos fatores tratamentos $[F(1,40)=0,34 ; p>0,05]$ e interação entre tratamentos versus sessões $[\mathrm{F}(1,40)=0,83 ; \mathrm{p}>0,05]$. A análise post-hoc de 
Duncan indicou que houve redução deste comportamento nos grupos S2 e M2 em relação aos seus grupos correspondentes em T1.

Com relação à imobilidade, a ANOVA de duas vias mostrou que houve diferença estatisticamente significativa no fator tratamentos $[F(1,40)=5,7 ; p<0,05]$. Nenhuma diferença estatisticamente significativa foi observada nos fatores sessões $[F(1,40)=0,73 ; p>0,05]$ e interação entre tratamentos versus sessões $[F(1,40)=2,35 ; \mathrm{p}>0,05]$.

Quanto ao esquadrinhamento, a ANOVA de duas vias mostrou que houve diferença estatisticamente significativa no fator sessões $[F(1,40)=5,07 ; p<0,05]$. Nenhuma diferença estatisticamente significativa foi observada nos fatores tratamentos $[F(1,40)=0,002 ; p>0,05]$ e interação entre tratamentos versus sessões $[F(1,40)=0,008 ; p>0,05]$.

Com relação ao espreitamento, a ANOVA de duas vias mostrou que não houve diferença estatisticamente significativa nos fatores tratamentos $\left[F_{(1,40)}=2,83 ; p>0,05\right]$, sessões $[F(1,40)=3,96 ; p>0,05]$ e interação entre tratamentos versus sessões $[F(1,40)=0,02 ; p$ $>$ 0,05]. Da mesma forma para autolimpeza, a ANOVA de duas vias mostrou que não houve diferença estatisticamente significativa nos fatores tratamentos $[F(1,40)=1,26$; $p>0,05]$, sessões $[F(1,40)=1,03 ; p>0,05]$ e interação entre tratamentos versus sessões $[F(1,40)=0,48 ; p$ $>$ 0,05]. O mesmo acontece para o levantamento, a ANOVA de duas vias mostrou que não houve diferença estatisticamente significativa nos fatores tratamentos $\left[\mathrm{F}_{(1,40)}=0,12 ; \mathrm{p}>\right.$ $0,05]$, sessões $[F(1,40)=0,01 ; p>0,05]$ e interação entre tratamentos versus sessões $[F(1,40)=$ $0,01 ; \mathrm{p}>0,05]$. 

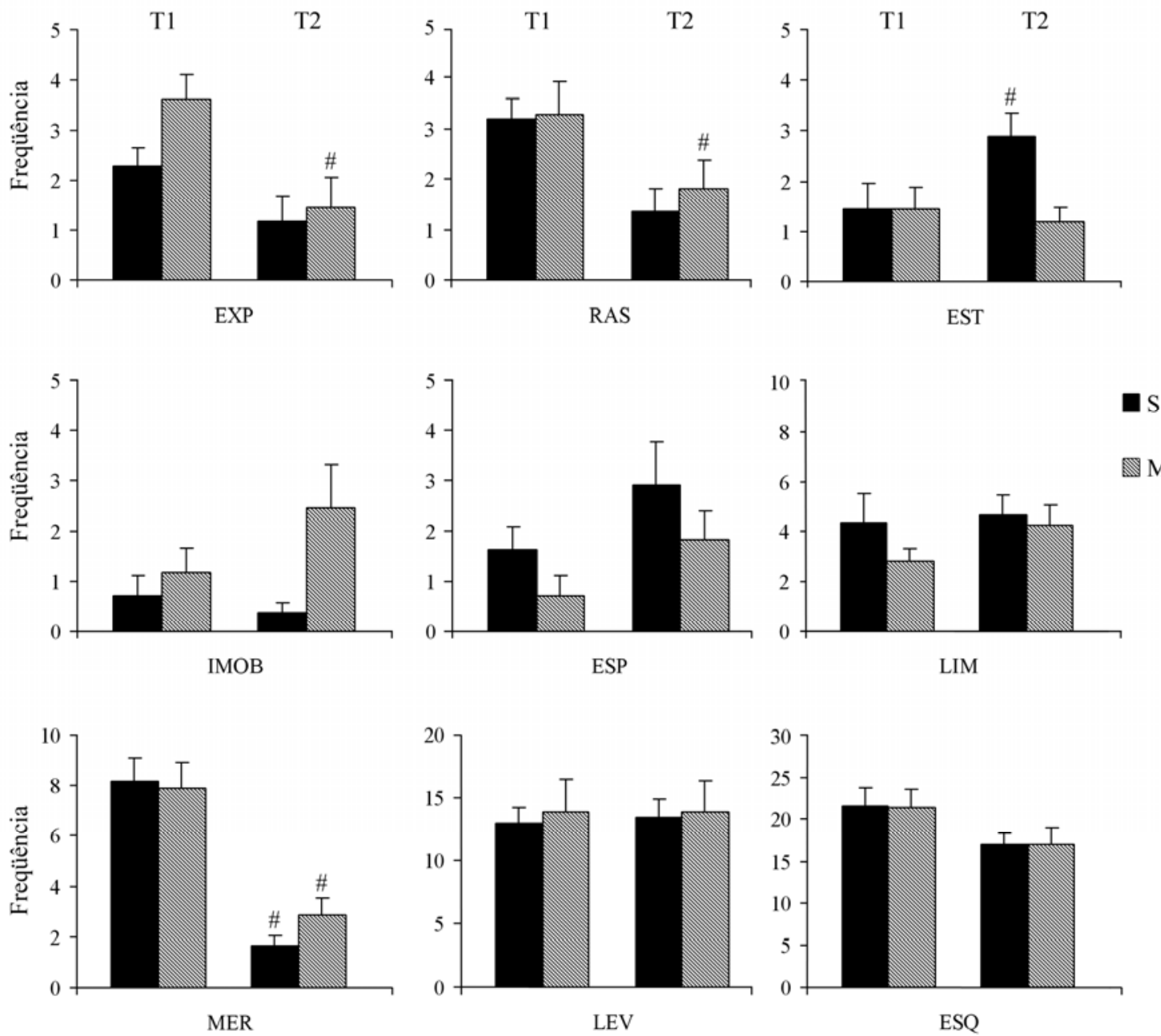

Figura 2: Efeito do $\mathrm{M}(0,5 \mathrm{mg} / \mathrm{Kg}$, i.p.) sobre o comportamento exploratório de ratos submetidos à primeira (T1) e segunda (T2) sessões no LCE. EXP = exploração da extremidade aberta; RAS = rastejamento; $\mathrm{EST}$ = esticamento; IMOB = imobilidade; $\mathrm{ESP}$ = espreitamento; LIM = autolimpeza; MER = mergulho da cabeça; LEV = levantamento e ESQ = esquadrinhamento. Cada animal recebeu uma injeção 15 minutos antes da T1 e T2 com 24 horas de intervalo. As barras representam as médias + EPM. S: salina e M: midazolam. \# p < 0,05 diferente dos grupos correspondentes em T1. ANOVA de duas vias seguida pelo teste post-hoc de Duncan. $\mathrm{N}=11$ animais para cada grupo. 


\section{Análise Neuroquímica}

\section{Córtex Pré-frontal}

As figuras 3A, 3B e 3C mostram os efeitos do tratamento com midazolam sobre o conteúdo de 5-HT, DA e NA, respectivamente, no córtex pré-frontal de ratos submetidos ao teste do LCE. No conteúdo de 5-HT e seu respectivo metabólito, 5-HIAA, a ANOVA de uma via mostrou que houve diferença estatisticamente significativa entre os efeitos dos tratamentos sobre os conteúdos de 5-HT $\left[\mathrm{F}_{(4,35)}=3,01 ; \mathrm{p}<0,05\right]$ e 5-HIAA $\left[\mathrm{F}_{(4,35)}=5,86 ; \mathrm{p}<0,05\right]$. A análise post-hoc de Duncan indicou que houve redução dos conteúdos de 5-HT e 5-HIAA nos grupos S1, M1, S2 e M2, em relação ao grupo não exposto ao LCE (C).

No conteúdo de DA e seus respectivo metabólito, DOPAC, a ANOVA de uma via mostrou que não houve diferença estatisticamente significativa entre os efeitos dos tratamentos sobre os conteúdos de DA $\left[\mathrm{F}_{(4,35)}=0,55 ; \mathrm{p}>0,05\right]$ e DOPAC $[\mathrm{F}(4,35)=1,03 ; \mathrm{p}>$ $0,05]$.

No conteúdo de NA, a ANOVA de uma via mostrou que houve diferença estatisticamente significativa entre os efeitos dos tratamentos $[F(4,35)=2,98$; p $<0,05]$. A análise post-hoc de Duncan indicou que houve redução do conteúdo de NA nos grupos S1 e M1 em relação ao grupo não exposto ao LCE (C).

Com relação às taxas de renovação de 5-HT e DA, a ANOVA de uma via mostrou que não houve diferença estatisticamente significativa entre os efeitos dos tratamentos $[\mathrm{F}(4,35)=$ 0,47; $\mathrm{p}>0,05]$ e $[\mathrm{F}(4,35)=1,87 ; \mathrm{p}>0,05]$, respectivamente (Figura 3D). 


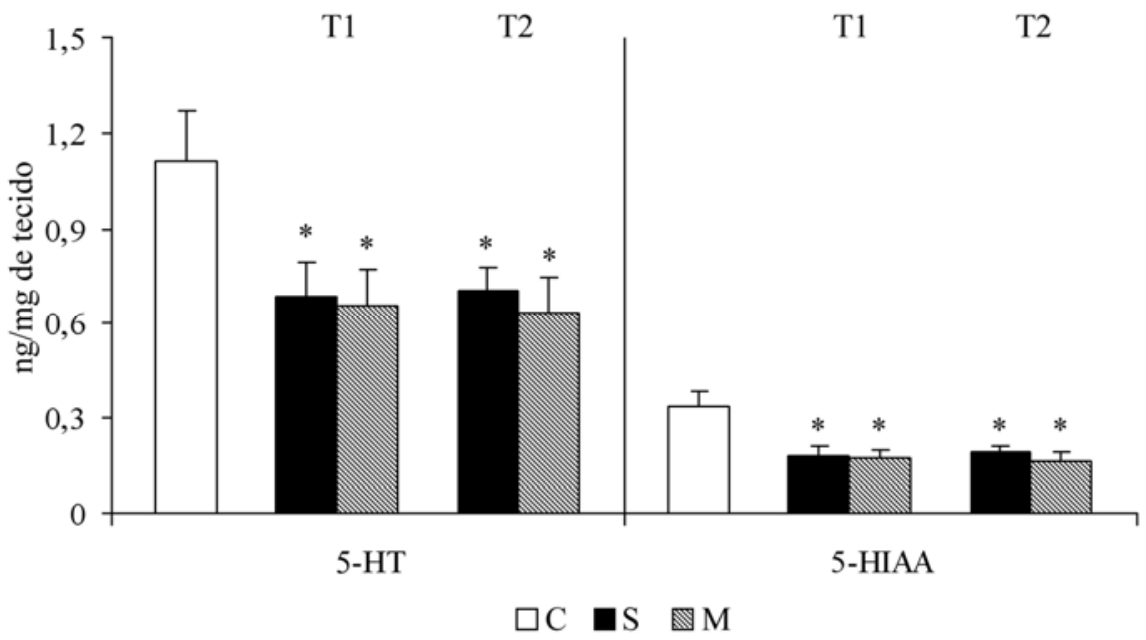

Figura 3A: Conteúdo de 5-HT e seu metabólito medidos no córtex pré-frontal em animais tratados com midazolam (0,5 mg/Kg, i.p.). Cada animal recebeu uma injeção 15 minutos antes de T1 e T2 com 24 horas de intervalo. As barras representam as médias + EPM. C: controle, S: salina e M: midazolam. ${ }^{*} \mathrm{p}<0,05$ diferente do grupo controle. ANOVA de uma via seguida pelo teste post-hoc de Duncan. $\mathrm{N}=8$ animais para cada grupo.

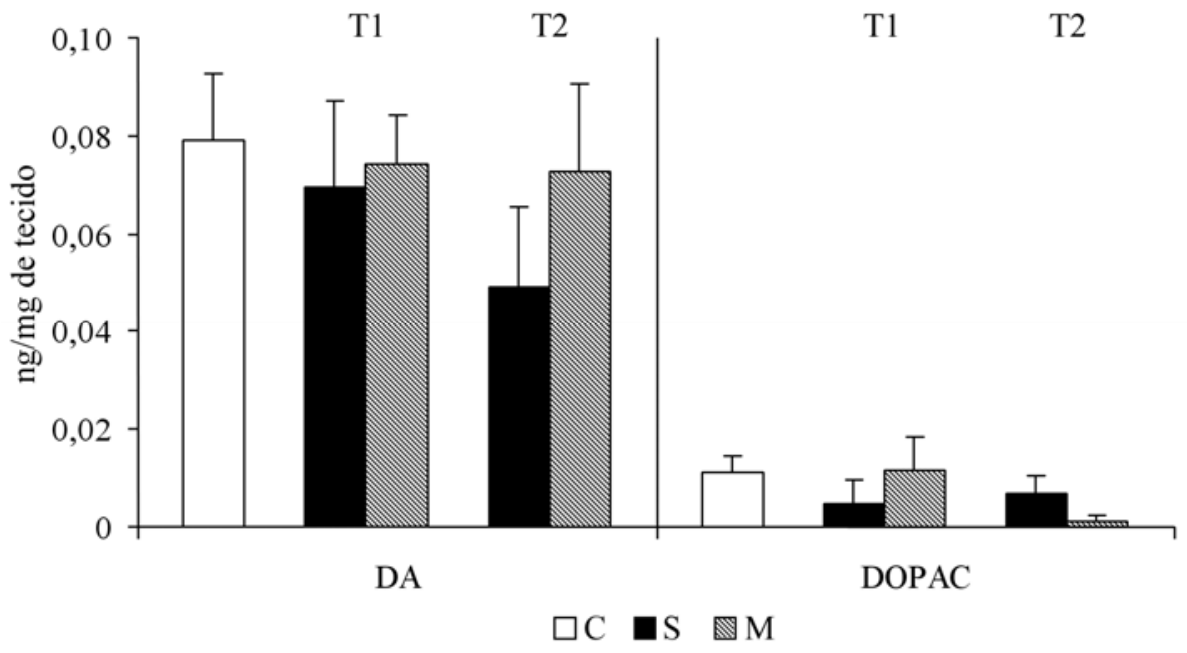

Figura 3B: Conteúdo de DA e seu metabólito medidos no córtex pré-frontal em animais tratados com midazolam (0,5 mg/Kg, i.p.). Cada animal recebeu uma injeção 15 minutos antes de T1 e T2 com 24 horas de intervalo. As barras representam as médias + EPM. C: controle, S: salina e M: midazolam. $\mathrm{N}=8$ animais para cada grupo. 


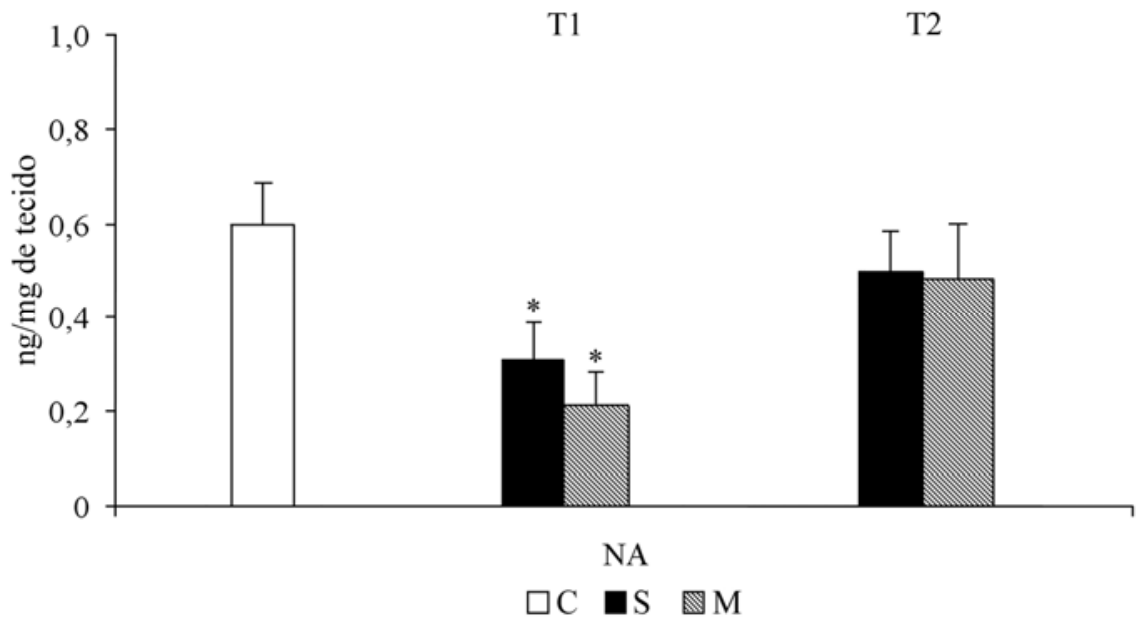

Figura 3C: Conteúdo de NA medidos no córtex pré-frontal em animais tratados com midazolam (0,5 $\mathrm{mg} / \mathrm{Kg}$, i.p.). Cada animal recebeu uma injeção 15 minutos antes de T1 e T2 com 24 horas de intervalo. As barras representam as médias + EPM. C: controle, $S$ : salina e M: midazolam. ${ }^{*} \mathrm{p}<0,05$ diferente do grupo controle. ANOVA de uma via seguida pelo teste post-hoc de Duncan. $\mathrm{N}=8$ animais para cada grupo.

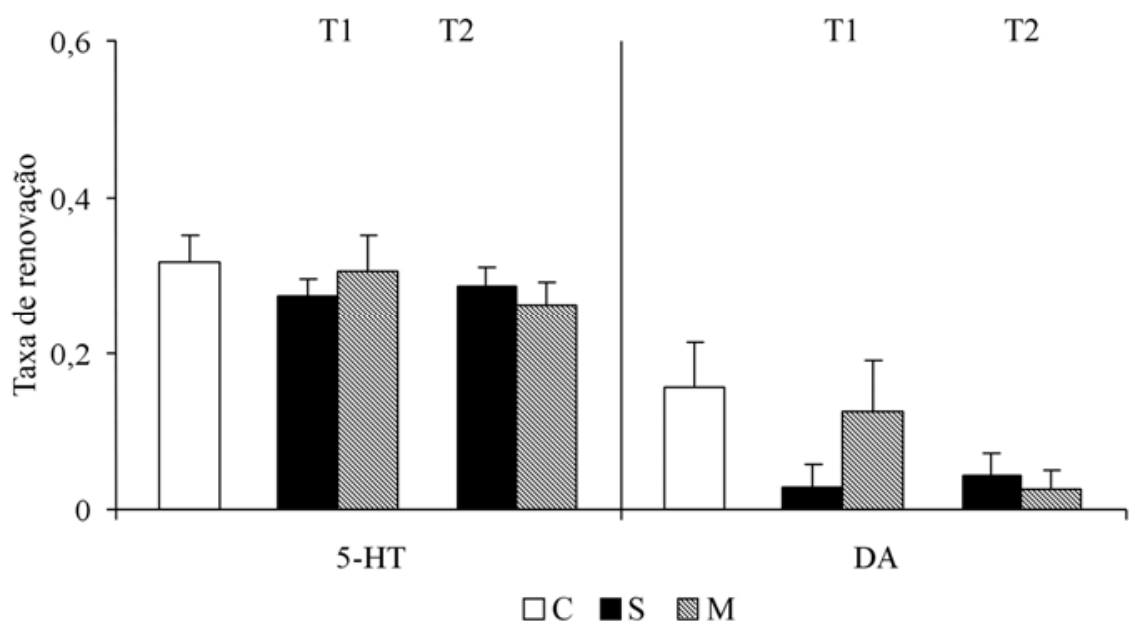

Figura 3D: Taxa de renovação de 5-HT e DA em relação aos seus metabólitos, 5-HIAA e DOPAC, medidos no córtex pré-frontal, em animais tratados com midazolam $(0,5 \mathrm{mg} / \mathrm{Kg}$, i.p.). Cada animal recebeu uma injeção 15 minutos antes de T1 e T2 com 24 horas de intervalo. Os valores representam as médias + EPM. C: controle, $S$ : salina e M: midazolam. $\mathrm{N}=8$ animais para cada grupo. 


\section{Amígdala}

As figuras 4A, 4B e 4C mostram os efeitos do tratamento com midazolam sobre o conteúdo de 5-HT, DA e NA, respectivamente, na amígdala de ratos submetidos ao teste do LCE. No conteúdo de 5-HT e seu respectivo metabólito, 5-HIAA, a ANOVA de uma via mostrou que houve diferença estatisticamente significativa entre os efeitos dos tratamentos sobre os conteúdos de 5-HT $[\mathrm{F}(4,35)=22,98 ; \mathrm{p}<0,05]$ e 5-HIAA $[\mathrm{F}(4,35)=24,75 ; \mathrm{p}<0,05]$. A análise post-hoc de Duncan indicou que houve redução dos conteúdos de 5-HT e 5-HIAA nos grupos S1, M1, S2 e M2 em relação ao grupo não exposto ao LCE (C).

No conteúdo de DA, a ANOVA de uma via mostrou que houve diferença estatisticamente significativa entre os efeitos dos tratamentos $[\mathrm{F}(4,35)=8,97 ; \mathrm{p}<0,05]$. A análise post-hoc de Duncan indicou que houve redução do conteúdo de DA nos grupos S1, M1, S2 e M2 em relação ao grupo não exposto ao LCE (C). Da mesma forma, a ANOVA de uma via mostrou que houve diferença estatisticamente significativa entre os efeitos dos tratamentos sobre o conteúdo de DOPAC $\left[\mathrm{F}_{(4,35)}=3,29 ; \mathrm{p}<0,05\right]$. A análise post-hoc de Duncan indicou que houve redução do conteúdo de DOPAC nos grupos S1, M1, M2 em relação ao grupo não exposto ao LCE (C).

No conteúdo de NA, a ANOVA de uma via mostrou que houve diferença estatisticamente significativa entre os efeitos dos tratamentos $[F(4,35)=5,16 ; p<0,05]$. A análise post-hoc de Duncan indicou que houve redução do conteúdo de NA nos grupos S1, M1, S2 e M2 em relação ao grupo não exposto ao LCE (C).

Com relação às taxas de renovação de 5-HT e de DA, a ANOVA de uma via mostrou que não houve diferença estatisticamente significativa entre os efeitos dos tratamentos $[\mathrm{F}(4,35)$ $=0,25 ; \mathrm{p}>0,05]$ e $[\mathrm{F}(4,35)=1,82 ; \mathrm{p}>0,05]$, respectivamente (Figura 4D). 


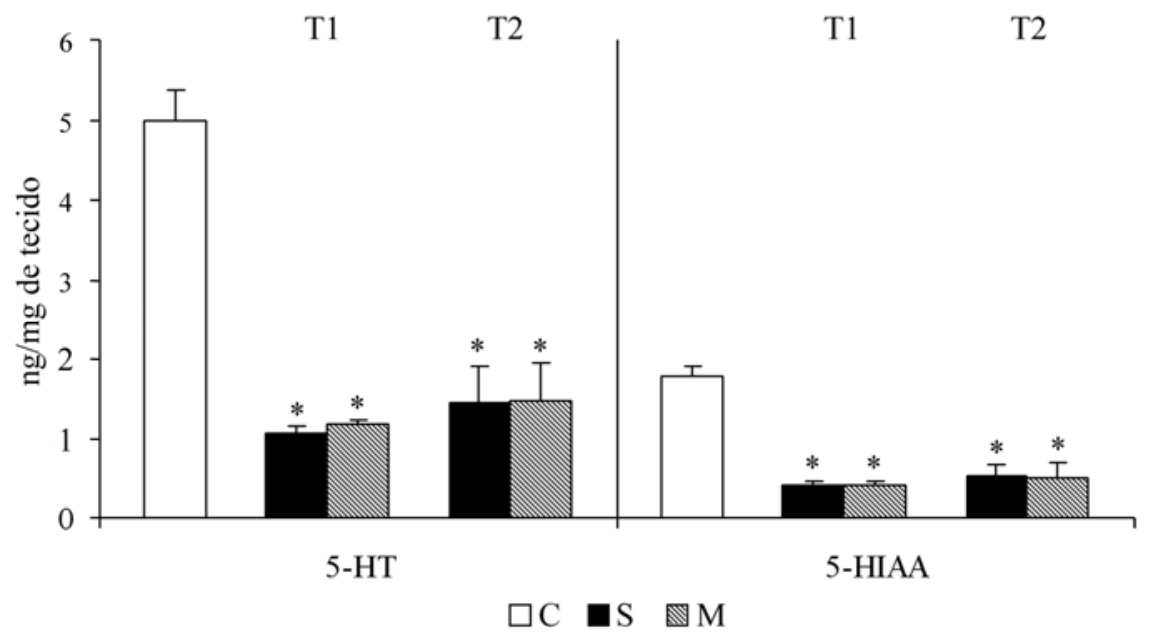

Figura 4A: Conteúdo de 5-HT e seu metabólito, medidos na amígdala em animais tratados com midazolam (0,5 mg/Kg, i.p.). Cada animal recebeu uma injeção 15 minutos antes de T1 e T2 com 24 horas de intervalo. As barras representam as médias + EPM. C: controle, S: salina e M: midazolam. * $\mathrm{p}<0,05$ diferente do grupo controle. ANOVA de uma via seguida pelo teste post-hoc de Duncan. $\mathrm{N}=$ 8 animais para cada grupo.

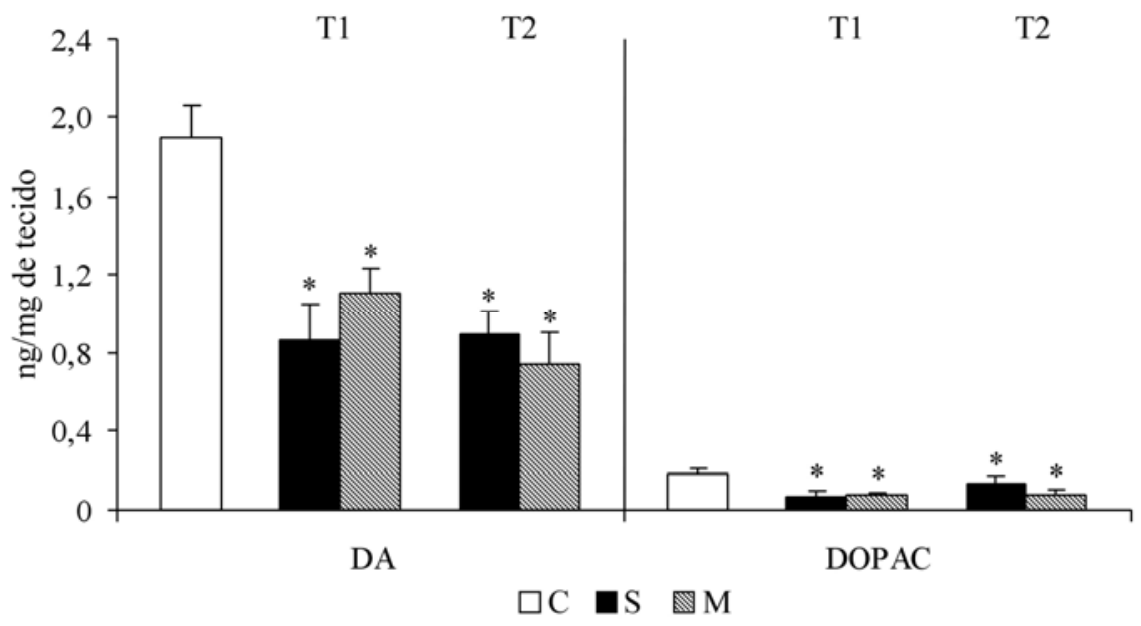

Figura 4B: Conteúdo de DA e seu metabólito medidos na amígdala em animais tratados com midazolam (0,5 mg/Kg, i.p.). Cada animal recebeu uma injeção 15 minutos antes de T1 e T2 com 24 horas de intervalo. As barras representam as médias + EPM. C: controle, S: salina e M: midazolam. * $\mathrm{p}<0,05$ diferente do grupo controle. ANOVA de uma via seguida pelo teste post-hoc de Duncan. $\mathrm{N}=$ 8 animais para cada grupo. 


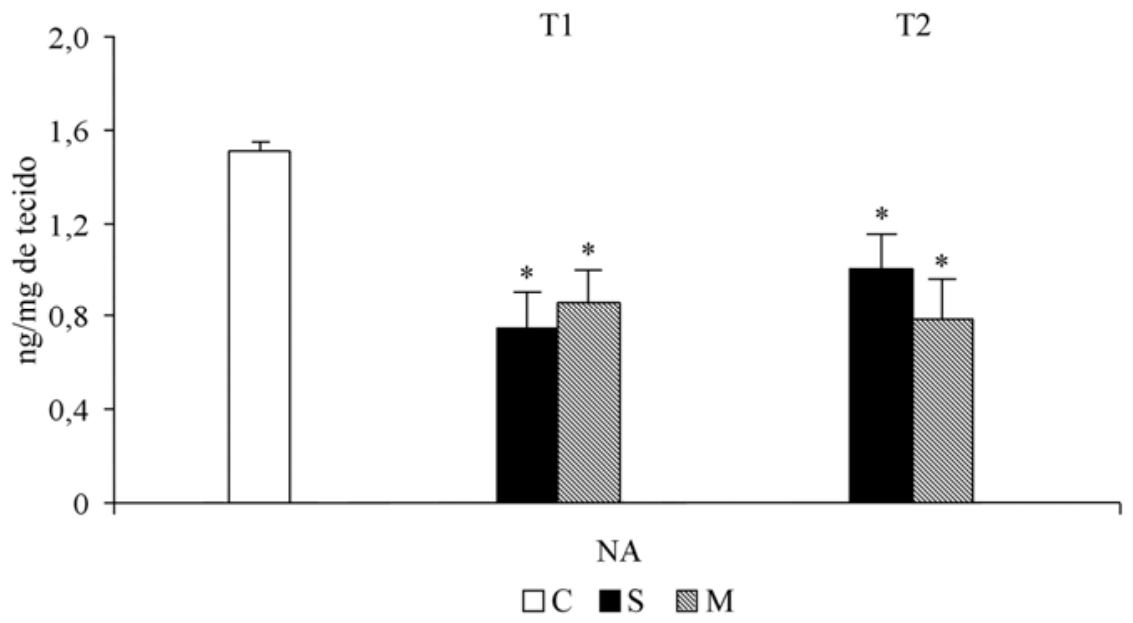

Figura 4C: Conteúdo de NA, na amígdala, em animais tratados com midazolam (0,5 mg/Kg, i.p.). Cada animal recebeu uma injeção 15 minutos antes de T1 e T2 com 24 horas de intervalo. As barras representam as médias + EPM. C: controle, $S$ : salina e M: midazolam. * $\mathrm{p}<0,05$ diferente do grupo controle. ANOVA de uma via seguida pelo teste post-hoc de Duncan. $\mathrm{N}=8$ animais para cada grupo.

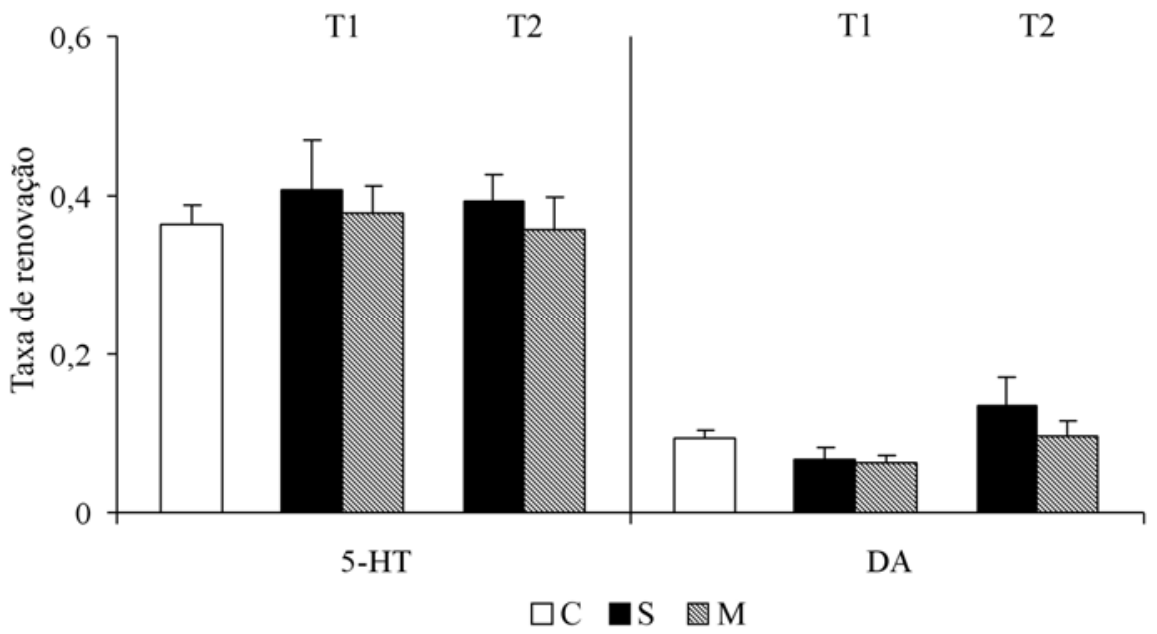

Figura 4D: Taxa de renovação de 5-HT e DA em relação aos seus metabólitos, 5-HIAA e DOPAC, medidos na amígdala, em animais tratados com midazolam $(0,5 \mathrm{mg} / \mathrm{Kg}$, i.p.). Cada animal recebeu uma injeção 15 minutos antes de T1 e T2 com 24 horas de intervalo. Os valores representam as médias + EPM. C: controle, S: salina e M: midazolam. $\mathrm{N}=8$ animais para cada grupo. 


\section{Hipocampo}

As figuras 5A, 5B e 5C mostram os efeitos do tratamento com midazolam sobre o conteúdo de 5-HT, DA e NA, respectivamente, no hipocampo de ratos submetidos ao teste do LCE. No conteúdo de 5-HT e seu respectivo metabólito, 5-HIAA, a ANOVA de uma via mostrou que houve diferença estatisticamente significativa entre os efeitos dos tratamentos sobre os conteúdos de 5-HT [F (4,35) = 16,38; p < 0,05] e 5-HIAA $[\mathrm{F}(4,35)=47,60 ; \mathrm{p}<0,05]$. O teste post-hoc de Duncan mostrou que houve redução dos conteúdos de 5-HT e 5-HIAA nos grupos S1, M1, S2 e M2 em relação ao grupo não exposto ao LCE (C).

No conteúdo de DA e seu respectivos metabólito, DOPAC, a ANOVA de uma via mostrou que não houve diferença estatisticamente significativa entre os efeitos dos tratamentos sobre o conteúdo de DA $\left[\mathrm{F}_{(4,35)}=0,52 ; \mathrm{p}>0,05\right]$ e DOPAC $\left[\mathrm{F}_{(4,35)}=0,95 ; \mathrm{p}>\right.$ $0,05]$.

No conteúdo de NA, a ANOVA de uma via mostrou que houve diferença estatisticamente significativa entre os efeitos dos tratamentos $[\mathrm{F}(4,35)=19,18 ; \mathrm{p}<0,05]$. $\mathrm{O}$ teste post-hoc de Duncan mostrou que houve redução do conteúdo de NA nos grupos S1, M1, S2 e M2 em relação ao grupo não exposto ao LCE (C).

Com relação às taxas de renovação de 5-HT e de DA, a ANOVA de uma via mostrou que não houve diferença estatisticamente significativa entre os efeitos dos tratamentos $[F(4,35)$ $=2,32 ; \mathrm{p}>0,05]$ e $[\mathrm{F}(4,35)=0,85 ; \mathrm{p}>0,05]$, respectivamente (Figura 5D). 


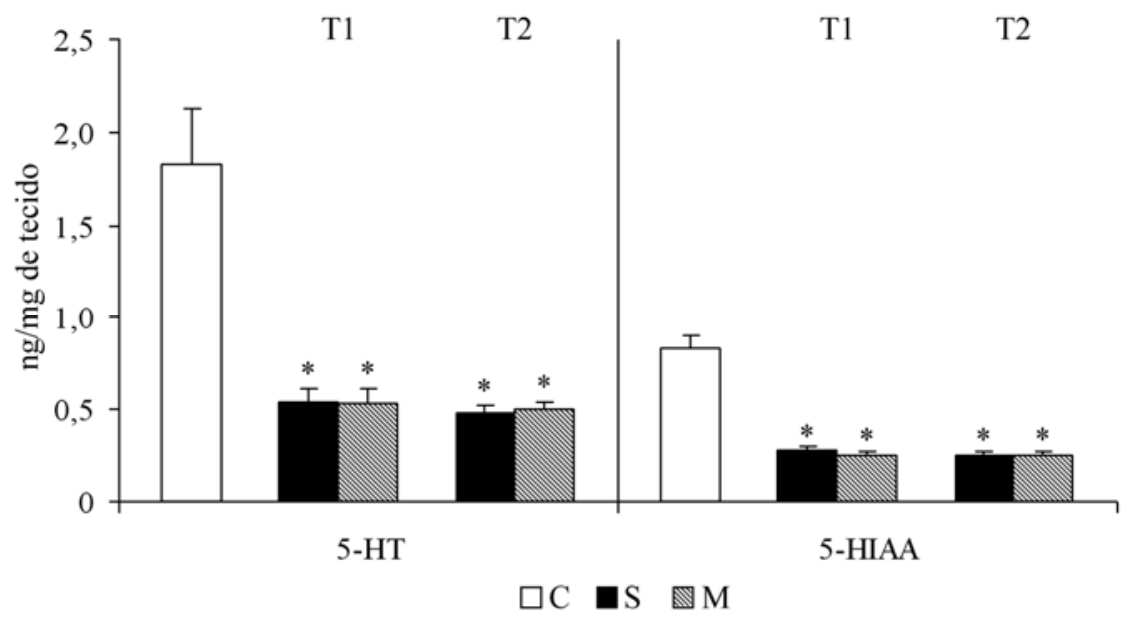

Figura 5A: Conteúdo de 5-HT e seu metabólito, medidos no hipocampo, em animais tratados com midazolam (0,5 mg/Kg, i.p.). Cada animal recebeu uma injeção 15 minutos antes de T1 e T2 com 24 horas de intervalo. As barras representam as médias + EPM. C: controle, S: salina e M: midazolam.* $\mathrm{p}<0,05$ diferente do grupo controle. ANOVA de uma via seguida pelo teste post-hoc de Duncan. $\mathrm{N}=$ 8 animais para cada grupo.

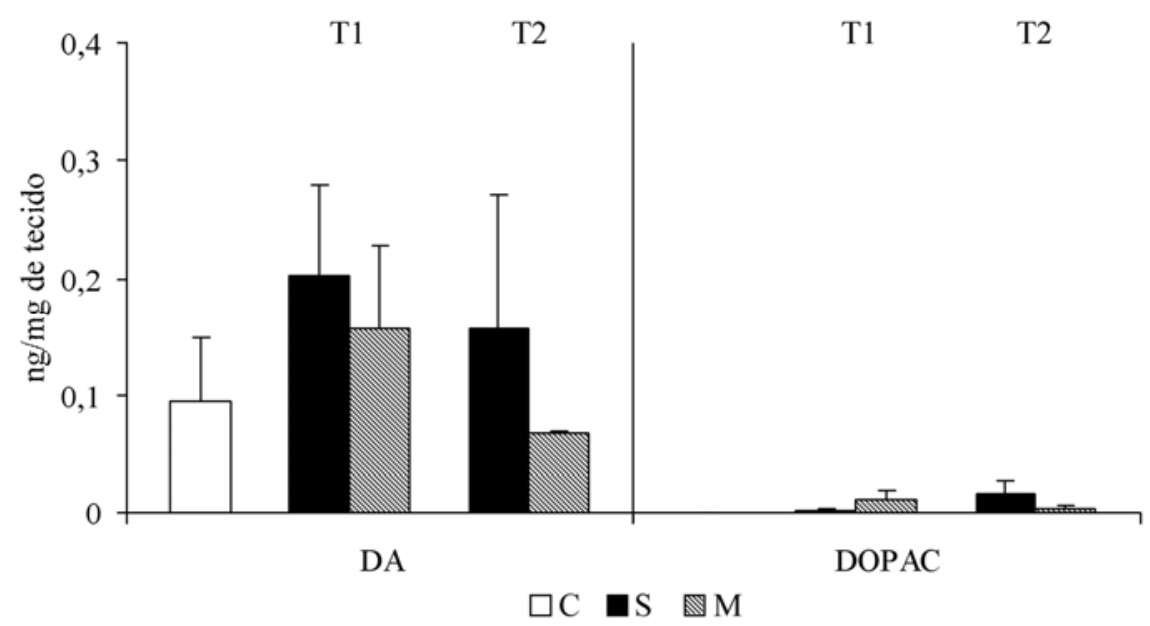

Figura 5B: Conteúdo de DA e seu metabólito medidos no hipocampo em animais tratados com M (0,5 mg/Kg, i.p.). Cada animal recebeu uma injeção 15 minutos antes de T1 e T2 com 24 horas de intervalo. As barras representam as médias + EPM. C: controle, $S$ : salina e M: midazolam. $\mathrm{N}=8$ animais para cada grupo. 


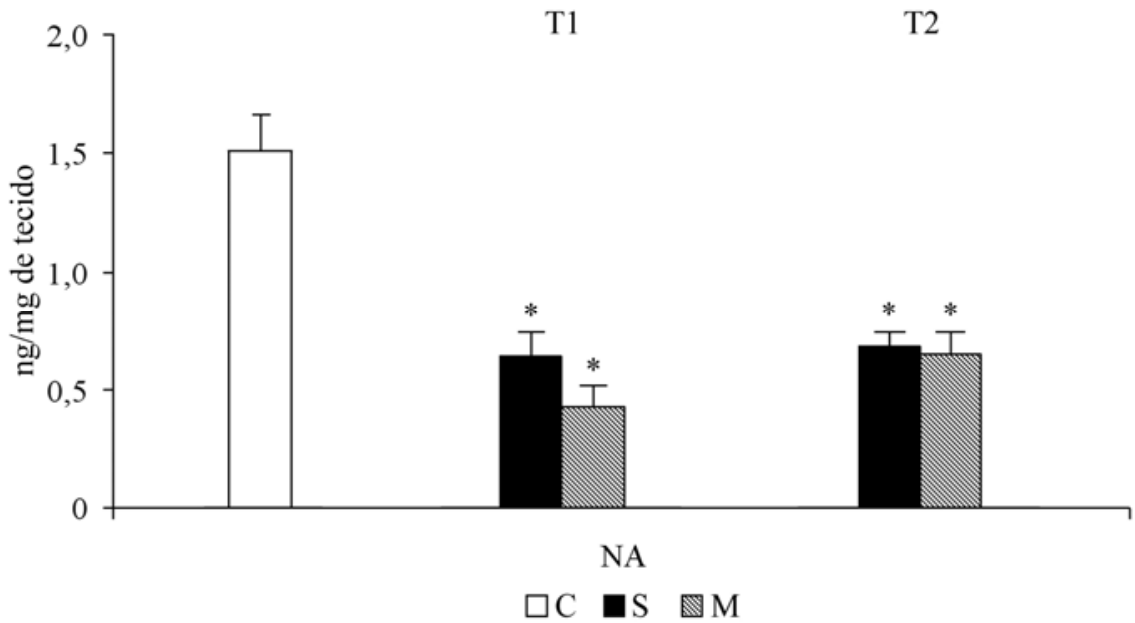

Figura 5C: Conteúdo de NA no hipocampo em animais tratados com midazolam (0,5 mg/Kg, i.p.). Cada animal recebeu uma injeção 15 minutos antes de T1 e T2 com 24 horas de intervalo. As barras representam as médias + EPM. C: controle, $S$ : salina e M: midazolam. * $\mathrm{p}<0,05$ diferente do grupo controle. ANOVA de uma via seguida pelo teste post-hoc de Duncan. $\mathrm{N}=8$ animais para cada grupo.

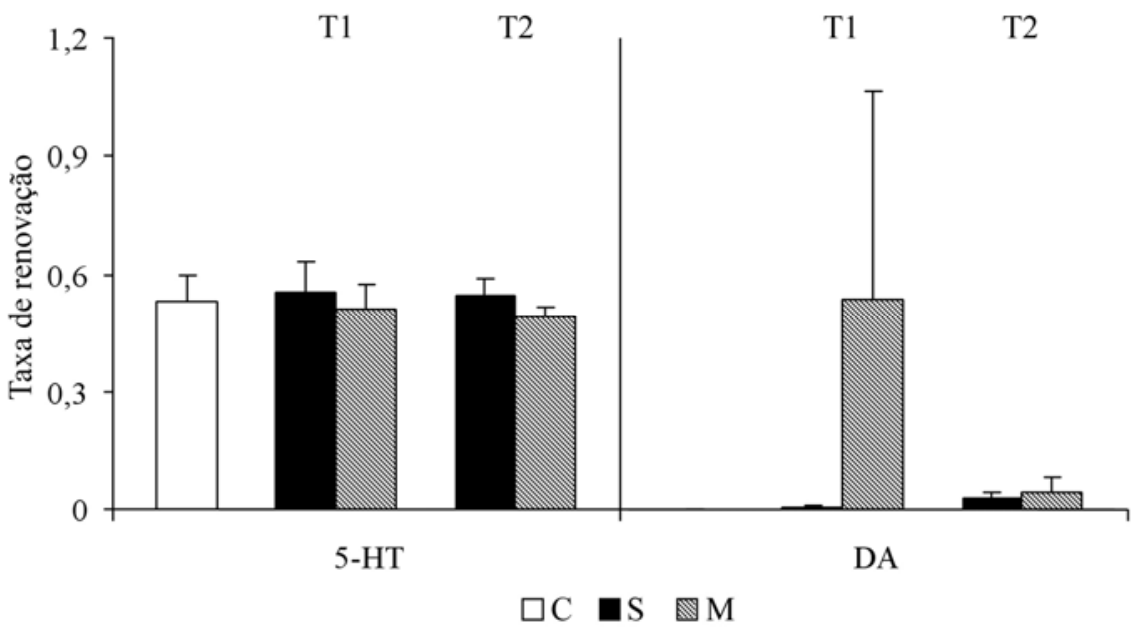

Figura 5D: Taxa de renovação de 5-HT e DA em relação aos seus metabólitos, 5-HIAA e DOPAC, medidos no hipocampo, em animais tratados com midazolam (0,5 mg/Kg, i.p.). Cada animal recebeu uma injeção 15 minutos antes de T1 e T2 com 24 horas de intervalo. Os valores representam as médias + EPM. C: controle, $S$ : salina e M: midazolam. $\mathrm{N}=8$ animais para cada grupo. 


\section{Núcleo accumbens}

As figuras 6A, 6B e 6C mostram os efeitos do tratamento com midazolam sobre o conteúdo de 5-HT, DA e NA, respectivamente, no núcleo accumbens de ratos submetidos ao teste do LCE. No conteúdo de 5-HT e seu respectivo metabólito, 5-HIAA, a ANOVA de uma via mostrou que houve diferença estatisticamente significativa entre os efeitos dos tratamentos sobre os conteúdos de 5-HT [F (4,35) = 10,12; p < 0,05] e 5-HIAA $[\mathrm{F}(4,35)=12,61 ; \mathrm{p}<0,05]$. A análise post-hoc de Duncan indicou que houve redução dos conteúdos de 5-HT e 5-HIAA nos grupos S1, M1, S2 e M2 em relação ao grupo não exposto ao LCE (C).

Quanto ao conteúdo de DA e seu respectivo metabólito, DOPAC, a ANOVA de uma via mostrou que não houve diferença estatisticamente significativa entre os efeitos dos tratamentos sobre os conteúdos de DA $\left[\mathrm{F}_{(4,35)}=1,37 ; \mathrm{p}>0,05\right]$ e DOPAC $[\mathrm{F}(4,35)=1,25 ; \mathrm{p}>$ $0,05]$.

No conteúdo de NA, a ANOVA de uma via mostrou que não houve diferença estatisticamente significativa entre os efeitos dos tratamentos $[\mathrm{F}(4,35)=1,79 ; \mathrm{p}>0,05]$.

Com relação às taxas de renovação de 5-HT e de DA, a ANOVA de via mostrou que não houve diferença estatisticamente significativa entre os efeitos dos tratamentos $[\mathrm{F}(4,35)=$ 1,34; $\mathrm{p}>0,05]$ e $[\mathrm{F}(4,35)=0,85 ; \mathrm{p}>0,05]$, respectivamente (Figura 6D). 


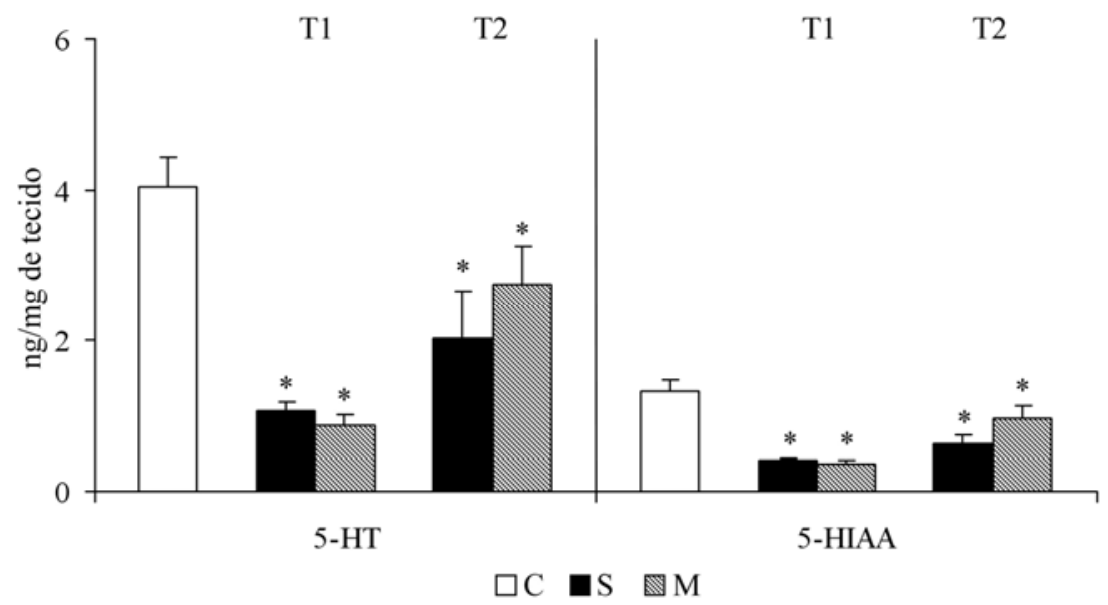

Figura 6A: Conteúdo de 5-HT e seu metabólito medidos no núcleo accumbens em animais tratados com midazolam (0,5 mg/Kg, i.p.). Cada animal recebeu uma injeção 15 minutos antes de T1 e T2 com 24 horas de intervalo. As barras representam as médias + EPM. C: controle, S: salina e M: midazolam. ${ }^{*} \mathrm{p}<0,05$ diferente do grupo controle. ANOVA de uma via seguida pelo teste post-hoc de Duncan. $\mathrm{N}=8$ animais para cada grupo.

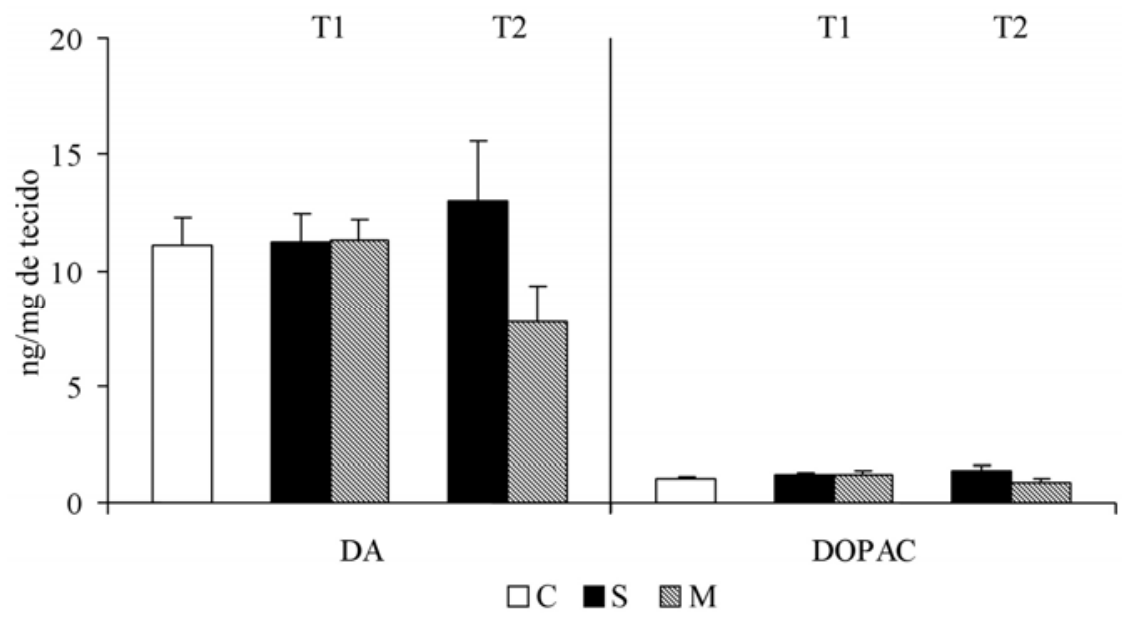

Figura 6B: Conteúdo de DA e seu metabólito medidos no núcleo accumbens em animais tratados com midazolam (0,5 mg/Kg, i.p.). Cada animal recebeu uma injeção 15 minutos antes de T1 e T2 com 24 horas de intervalo. As barras representam as médias + EPM. C: controle, S: salina e M: midazolam. $\mathrm{N}=8$ animais para cada grupo. 


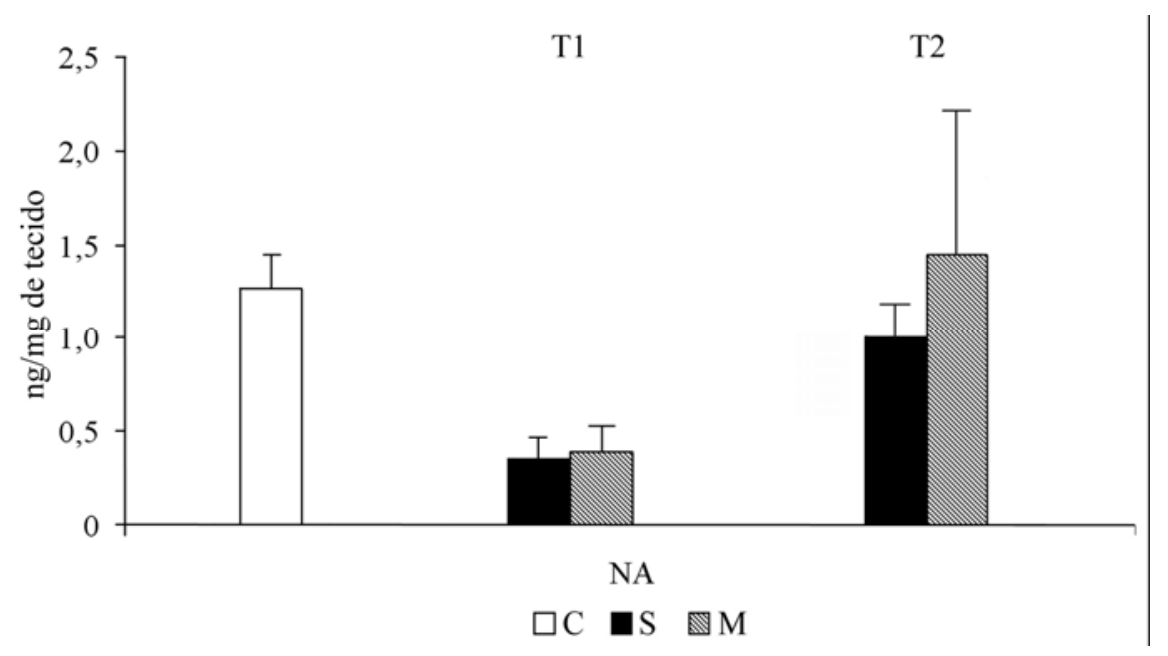

Figura 6C: Conteúdo de NA no núcleo accumbens em animais tratados com midazolam $(0,5 \mathrm{mg} / \mathrm{Kg}$, i.p.). Cada animal recebeu uma injeção 15 minutos antes de T1 e T2 com 24 horas de intervalo. As barras representam as médias + EPM. C: controle, $S$ : salina e M: midazolam. $\mathrm{N}=8$ animais para cada grupo.

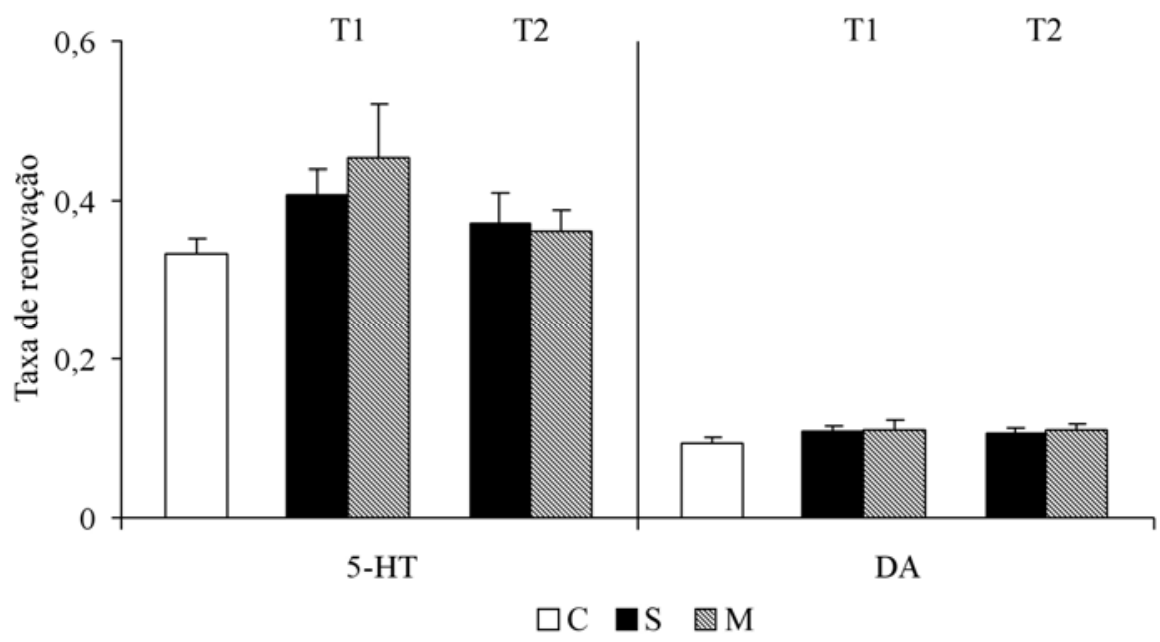

Figura 6D: Taxa de renovação de 5-HT e DA em relação aos seus metabólitos, 5-HIAA e DOPAC, medidos no núcleo accumbens, em animais tratados com midazolam $(0,5 \mathrm{mg} / \mathrm{Kg}$, i.p.). Cada animal recebeu uma injeção 15 minutos antes de T1 e T2 com 24 horas de intervalo. Os valores representam as médias + EPM. C: controle, $S$ : salina e M: midazolam. $\mathrm{N}=8$ animais para cada grupo. 
Discussão 
A primeira exposição ao LCE influenciou as respostas comportamentais e farmacológicas dos animais na segunda exposição a este teste. A administração de midazolam antes da primeira sessão experimental promoveu um efeito ansiolítico, aumentando a exploração dos braços abertos sem, porém, aumentar a atividade exploratória dos animais nos braços fechados. Esse efeito ansiolítico pôde ser detectado também na porcentagem de entradas e tempo de permanência nos braços abertos. Na segunda sessão, foi observado um padrão comportamental completamente diferente da primeira sessão: uma clara diminuição na exploração dos braços abertos, (indicada pela diminuição do número de entradas e tempo de permanência nestes braços), corroborando resultados prévios (BERTOGLIO; CAROBREZ, 2002c; FRUSSA-FILHO; RIBEIRO, 2002; HOLMES; RODGERS, 1999; GONZALEZ; FILE, 1997; FILE, 1990). O efeito ansiolítico do midazolam no teste do LCE não foi obtido quando a droga foi administrada antes da segunda sessão experimental, confirmando relatos anteriores da ineficácia dos BDZs nesta condição (LISTER, 1987; FILE, 1990; FILE; ZANGROSSI, 1993; HOLMES; RODGERS, 1998; CRUZ-MORALES; SANTOS; BRANDÃO, 2002).

Há inúmeras hipóteses que tentam explicar este fenômeno conhecido como OTT, dentre essas: i) Habituação ao teste por exposição repetida aos mesmos estímulos contextuais. Neste sentido, Dawson et al. (1994) argumentaram que a baixa eficácia dos BDZs na segunda sessão é devida a habituação à situações novas expressa pela redução da atividade locomotora, medida pela distância percorrida pelo animal no LCE durante o tempo do teste. ii) Conflito entre explorar ambientes novos e medo de espaços abertos seguido de evitação dos mesmos. Esta hipótese foi sugerida com base no fato de que a completa exploração de um ambiente novo é essencial para garantir um lugar seguro e a exploração dos arredores serve para certificar-se de que o lugar é realmente seguro. Assim, na segunda exposição o animal reconhece que o braço fechado do LCE é um lugar seguro, razão pela qual evita a exploração 
dos braços abertos. Isso caracteriza a ausência de conflito tipo aproximação/ evitação na segunda exposição (RODGERS; SHEPHERD, 1993). Em outras palavras, o prévio conhecimento do labirinto (como por exemplo, a informação de que não é possível escapar por meio dos braços abertos) diminui a tendência em explorar áreas potencialmente aversivas, por isso, reduz o conflito e, conseqüentemente, a ansiedade, eliminando os possíveis efeitos ansiolíticos dos BDZs. Apoiando tal hipótese, há relatos de que a introdução de elementos geradores de conflito, na segunda exposição, é capaz de reinstalar a eficácia dos BDZs (PEREIRA et al., 1999).

Uma outra forma de analisar a ausência dos efeitos ansiolíticos dos BZDs na segunda exposição ao LCE (OTT) é a partir do surgimento de medo intenso, na segunda sessão, decorrente da primeira exposição, o que leva a evitação fóbica aos braços abertos, condição essa insensível aos efeitos dos BZDs. Em outras palavras, a ausência do efeito ansiolítico dos BZDs na segunda exposição ao LCE é devido a ineficácia desses compostos sobre o medo, predominante na segunda sessão (CRUZ-MORALES; SANTOS; BRANDÃO, 2002 RODGERS; SHEPHERD, 1993; FILE, 1993; FILE; ZANGROSSI, 1993; FILE et al., 1993). O surgimento do medo intenso pode ser explicado através de comportamentos realizados pelo animal no LCE (ANSELONI et al., 1995). Desta forma, a análise por categorias comportamentais do presente trabalho, na segunda sessão, revela reduções estatisticamente significativas na freqüência dos comportamentos relacionados à exploração ambiental, como mergulho da cabeça e exploração da extremidade aberta. Segundo Treit, Menard e Royan (1993), mais do que a altura, a falta da tigmotaxia nos braços abertos é o principal fator que promove a evitação.

A literatura oferece vários trabalhos que fortalecem a hipótese do surgimento do medo intenso na segunda exposição ao LCE. Segundo Pellow et al. (1985), animais confinados nos braços abertos apresentam mais defecação, congelamento e diminuem a exploração do 
labirinto, mais do que aqueles que são confinados nos braços fechados. File, Mabbutt e Hitchcott (1990) sugeriram que a experiência inicial aos braços abertos é crucial para a baixa eficácia dos BZDs na segunda exposição ao LCE. Além desses últimos autores, Bertoglio e Carobrez (2000), sugeriram que há uma sensibilização da aversão aos braços abertos do LCE (medo incondicionado) a qual se refletiria na aquisição (aprendizagem) de uma resposta de esquiva inibitória, desencadeada pela exploração de uma área (braços abertos) potencialmente perigosa. Esta resposta fundamentaria a mudança qualitativa na natureza da resposta comportamental observada durante a exploração subseqüente do LCE (FILE; ZANGROSSI, 1993; TREIT; MENARD; ROYAN, 1993; HOLMES; RODGERS, 1998) e, conseqüentemente, a sensibilidade à droga nesta sessão experimental (FILE, 1993; FILE et al., 1993; BERTOGLIO; CAROBREZ, 2002a, b, c; CRUZ-MORALES; SANTOS; BRANDÃO; 2002; BERTOGLIO; CAROBREZ, 2003). Entretanto, há trabalhos que não corroboram a hipótese do presente estudo. Holmes e Rodgers (1999) mostraram que o confinamento por 5 minutos dos animais nos braços abertos não compromete a eficácia ansiolítica do clordiazepóxido na segunda exposição ao LCE, após 24 horas de intervalo, ao contrário daqueles confinados nos braços fechados que mostraram o fenômeno da OTT. Fortalecendo esta hipótese, Frussa-Filho e Ribeiro (2002), mostraram que a primeira exposição ao LCE com quatro braços abertos não compromete a eficácia ansiolítica do clordiazepóxido na segunda exposição, ao contrário daqueles expostos ao LCE com quatro braços fechados que mostraram o fenômeno da OTT. Assim, foi sugerido que a experiência nos braços abertos não é crucial ao desenvolvimento do fenômeno da OTT e que este fenômeno não é devido à aquisição de evitação fóbica dos braços abertos e sim a uma experiência ao LCE como um todo.

Outra explicação para o fenômeno da OTT se refere à hipótese de Gonzales e File (1997), que sugere que a experiência ao LCE liberaria um agonista inverso endógeno que se 
ligaria e dessensibilizaria o receptor de BZDs e esta mudança seria manifestada na segunda exposição. Segundo Bertoglio e Carobrez (2002a), o fenômeno da OTT pode envolver

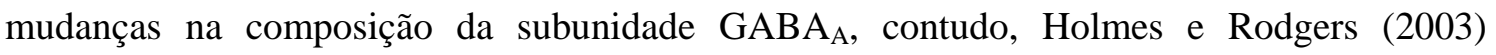
mostraram que o Flumazenil, um antagonista de receptor benzodiazepínico, foi ineficaz, tanto em camundongos com experiência no LCE, como em camundongos ingênuos expostos ao LCE. Esses autores argumentam que a baixa eficácia de agonistas e agonistas inversos benzodiazepínicos na segunda exposição ao LCE é devida ao não recrutamento do mecanismo GABA/ BZD durante a exposição ao LCE de animais previamente expostos.

Sabe-se também que mecanismos colinérgicos vêm sendo implicados em processos de aprendizagem e memória (DEUTSCH, 1971; BARTUS et al., 1985). Assim, com a administração da escopolamina, um antagonista não-seletivo de receptores muscarínicos, antes da primeira exposição, mas não após a primeira, ou antes, da segunda foi capaz de manter o efeito ansiolítico do midazolam na segunda exposição ao LCE (BERTOGLIO, 2004). Da mesma forma, altas doses de clordiazepóxido previamente à primeira sessão, previnem o fenômeno da OTT (FILE; MABBUTT; HITCHCOTT, 1990).

Os principais resultados no presente estudo neuroquímico foram: i) diminuição dos conteúdos de 5-HT e NA no córtex pré-frontal, na amígdala, no hipocampo e no núcleo accumbens depois da primeira e segunda exposição ao LCE; ii) diminuição do conteúdo de DA apenas na amígdala após a primeira e a segunda exposição ao LCE; iii) o midazolam não reverteu as reduções nos conteúdos dessas aminas durante as sessões; iv) essas reduções causadas pela exposição ao LCE não são devidas à exacerbação da degradação metabólica das aminas biogênicas. Estes resultados serão discutidos abaixo com base na literatura existente sobre este assunto.

De modo geral, está claro que a redução no conteúdo de 5-HT nas estruturas citadas acima está associada à primeira exposição ao LCE. Segundo Dominguez et al. (2003a, b), a 
exposição ao LCE afeta a neurotransmissão serotoninérgica em áreas do sistema nervoso central envolvidas com a memória do evento aversivo, promovendo redução da atividade serotoninérgica nos núcleos dorsal e mediano da rafe. Estes autores levantaram várias hipóteses que também podem ser utilizadas para explicar os resultados deste presente trabalho. Na primeira, consideram que todo tipo de estresse acarreta a liberação do fator liberador da corticotrofina. O núcleo dorsal da rafe apresenta redução da atividade serotoninérgica sob influência dos corticosteróides (PRICE et al., 1998; VALENTINO; LJOUTERMAN; VAN BOCKSTACLE, 2001; KIRBY; RICE; VALENTINO, 2000). Uma segunda possibilidade é que a liberação local neste núcleo estimula autoreceptores presentes em neurônios serotoninérgicos, resultando em um feed back negativo no sistema. O núcleo mediano da rafe também é afetado pela atividade de autoreceptores, apesar de existir estudos que mostram que os neurônios deste núcleo são menos sensíveis à ação nos autoreceptores 5HT $_{1 A}$ (HJORTH; SHARP, 1991). Como terceira alternativa, ocorreria a liberação de 5-HT para os espaços extracelulares durante o teste do LCE, que não seriam detectados em estudos post-mortem como este. Esta condição se refletiria na ausência de efeitos significativos nas taxas de renovação das aminas biogênicas nas estruturas analisadas. Apoiando esta última hipótese, estão as evidências que indicam os 2 primeiros minutos do teste do LCE como cruciais para determinar os efeitos ansiogênicos das exposições aos braços abertos e da altura do LCE (DAL-CÓL et al., 2003). Assim, pode-se imaginar que a atividade serotoninérgica esteja elevada nesses 2 primeiros minutos e que, se reduzam nos minutos subseqüentes até o sacrifício do animal.

A diminuição do conteúdo serotoninérgico no córtex pré-frontal, na amígdala, no hipocampo e no núcleo accumbens parece ser duradoura, pois permaneceu após a segunda exposição ao LCE, depois de 24 horas de intervalo entre as sessões. Esses dados corroboram ao trabalho de Sajdyk, Katner e Shekar (1997), cuja redução duradoura da liberação de 5-HT, 
no hipotálamo dorsomedial, pode ser atribuída a mecanismos compensatórios que acontecem seguidamente ao aumento da liberação deste neurotransmissor. Ainda, resultados similares foram recentemente obtidos em estudos que mostraram a redução na transmissão serotoninérgica no núcleo dorsal da rafe de ratos sacrificados imediatamente ou 10-12 dias depois de serem submetidos ao teste do LCE. Esta redução no funcionamento das vias serotoninérgicas originárias no núcleo dorsal da rafe determina, obviamente, menor síntese e armazenamento de 5-HT em suas áreas límbicas de projeção (DOMINGUEZ et al., 2003a, b).

Os mecanismos serotoninérgicos do sistema límbico, particularmente ao nível da amígdala, são cruciais no processo de informação aversiva (GOLDSTEIN et al., 1996; GRAEFF; DEAKIN, 1991; DEAKIN; GRAEFF; GUIMARAES, 1992). Na amígdala houve redução dos conteúdos de 5-HT, DA e NA, após a primeira e segunda exposição ao LCE. Uma possível interpretação para estes resultados é considerar que a amígdala funciona como uma interface cognitiva - emocional, pois além de receber projeções do bulbo olfatório, também as recebe do neocórtex (áreas de associação). Suas aferências comunicam-se diretamente com o hipotálamo e matéria cinzenta periaquedutal na qual controla respostas neurohumoral, comportamental e autonômica. Segundo Fanselow (1991), esta estrutura avalia o grau de ameaça e envia o resultado desta avaliação para a substância cinzenta periaquedutal, que mais tarde seleciona e organiza a resposta defensiva apropriada. Considerando que estudos neuroanatômicos têm demonstrado que do núcleo central da amígdala partem projeções para a ATV (área que inerva o córtex pré-frontal), locus coeruleus e núcleos da rafe (GONZALES; CHESSELET, 1990; WALLACE; MAGNUSON; GRAY, 1992), que promovem a inervação aminérgica do sistema límbico, é possível afirmar que a amígdala tem algum papel regulatório crucial sobre todo o sistema neural responsável pelo comportamento emocional. 
O presente trabalho aponta novas evidências da participação de aminas biogênicas da amígdala na regulação do comportamento de ratos submetidos ao teste do LCE,. A amígdala foi a única estrutura entre as quatro estudadas neste trabalho que apresentou redução nos conteúdos das três aminas biogênicas, em ratos expostos a uma ou duas sessões no teste do LCE. É possível que a 5-HT, DA e NA, na amígdala, controlam o envolvimento das demais estruturas na geração e elaboração do comportamento defensivo induzido pelos estímulos aversivos do LCE.

Há trabalhos na literatura que mostram que a amigdalectomia bloqueia o aumento de DA no córtex pré-frontal em situações de estresse, o que sugere o envolvimento da amígdala no controle aferente de respostas emocionais mediadas pelo sistema mesocortical dopaminérgico (DAVIS et al., 1994; GOLDSTEIN et al., 1996). Esta hipótese é baseada na presença de conexões recíprocas entre o núcleo basolateral e o córtex pré-frontal (KRETTEK; PRICE, 1977; MCDONALD, 1991).

Sabe-se que o núcleo central da amígdala envia projeções diretas e indiretas para o locus coeruleus, origem dos neurônios noradrenérgicos que inervam o córtex. Estudos imunohístoquímicos também têm demonstrado que neurônios positivos para tirosina hidroxilase, enzima envolvida na síntese de NA, no locus coeruleus recebem aferências do núcleo central da amígdala (WALLACE; MAGNUSON; GRAY, 1992). Alterações na transmissão noradrenérgica, também ocorreram neste estudo, em animais submetidos ao LCE. Houve redução significativa no conteúdo noradrenérgico do córtex pré-frontal após a primeira exposição ao LCE. A possível interpretação para este resultado é dificultada pela ausência de valores referentes ao metabólito da NA, o MHPG, que poderia, através da relação metabólito/ neurotransmissor, informar o estado funcional do processo de formação e degradação de NA após os testes. 
Da mesma forma que ocorre com o locus coeruleus, o núcleo central da amígdala envia projeções para o núcleo dorsal da rafe (WALLACE; MAGNUSON; GRAY, 1992). Assim, os neurônios serotoninérgicos do núcleo dorsal da rafe podem sofrer influência da amígdala com conseqüências importantes para o funcionamento do sistema serotoninérgico nas demais estruturas inervadas pelo núcleo dorsal da rafe (AZMITIA; SEGAL, 1978; MOORE; HALARIS; JONES, 1978). O presente resultado sugere que a exposição à altura e espaços abertos do LCE causa uma diminuição significativa da concentração serotoninérgica no córtex pré-frontal, sugerindo que a 5-HT, nesta área, possui algum papel na regulação das respostas emocionais (GRAEFF; DEAKIN, 1991; DEAKIN; GRAEFF; GUIMARAES, 1992). Desta forma, o decréscimo da neurotransmissão serotoninérgica do córtex pré-frontal pode estar envolvido na desconexão comportamental que leva a resultados aversivos. De forma similar, os conteúdos serotoninérgicos no córtex pré-frontal, após a segunda exposição ao LCE, foram mantidos significativamente baixos. Esta redução pode estar associada à dificuldade do animal em enfrentar situações estressantes decorrentes da experiência repetida no LCE.

O córtex pré-frontal é uma região crucial no estabelecimento de processos cognitivos e de tomada de decisão determinadas com base no valor do estímulo (GOLDMAN-RAKIC, 1995). Foi sugerido que a exposição a uma grande variedade de estímulos estressantes agudos determina um aumento da transmissão dopaminérgica nas vias mesocorticais (FEENSTRA; BOTTERBLOM; VAN UUM, 1995; INOUE; TSUCHIYA; KOYAMA, 1996; GOLDSTEIN et al., 1996; CUADRA et al., 1999, 2001; MILLAN, 2003). Além disso, a ativação de neurônios dopaminérgicos está envolvida no estabelecimento de processos adaptativos à estimulação de medo inato (ESPEJO, 1997; MORROW et al., 1999). O presente estudo mostrou que não houve aumento significativo no conteúdo dopaminérgico no córtex préfrontal de ratos expostos uma ou duas vezes ao LCE. Enquanto o presente estudo não oferece 
respaldo direto às descobertas citadas acima na medida que a análise post-mortem não nos permite inferir sobre a transmissão dopaminérgica nas vias mesocorticais, outro estudo deste laboratório permite, através do uso da técnica de microdiálise, mostrar um aumento dos níveis extracelulares de DA no córtex pré-frontal após a estimulação aversiva incondicionada do colículo inferior, uma estrutura que pertence ao sistema cerebral aversivo (CUADRA et al., 2000; BRANDÃO et al., 2003).

Vários pesquisadores têm tentado estabelecer um modelo integrativo que considera as estruturas límbicas e o sistema monoaminérgico para explicar as reações de defesa dos indivíduos frente a situações estressantes e perigosas. Alterações na mediação monoaminérgica destes circuitos límbicos também têm sido usadas no estudo da neurobiologia da ansiedade. Por exemplo, alterações nos sistemas monoaminérgicos de estruturas que se comunicam com o núcleo accumbens, como o córtex pré-frontal e a amígdala, devem contribuir ao surgimento dos sintomas de alguns tipos de desordens da ansiedade, como a Desordem do Estresse Pós-Traumático e a Depressão (CHARNEY et al., 1993; SOUTHWICK et al., 1993; GOLDSTEIN et al., 1994, 1996; POST, 1992; CHROUSOS; GOLD, 1992). Segundo Brandão et al. (2003), a estimulação aversiva repetitiva é considerada uma das maiores fontes de certos tipos de depressão, muito bem estabelecida pelos modelos animais de depressão, tais como, o teste do nado forçado, a estimulação aversiva crônica de estruturas cerebrais, etc. Por exemplo, administração crônica de fluoxetina, por duas semanas, em animais submetidos à estimulação elétrica da matéria cinzenta periaquedutal dorsal, atenua somente o congelamento, mas não a fuga (BORELLI et al., 2004).

Considerando que a ação regulatória da 5-HT sobre o estado emocional em situações estressantes deva constituir um mecanismo subjacente à ação terapêutica dos antidepressivos, pode-se estabelecer uma relação entre os presentes resultados com o conceito de depressão. É 
neste contexto que este trabalho foi realizado. Esperamos, assim, que os presentes resultados venham contribuir para o entendimento dos processos neuroquímicos envolvidos no fenômeno de OTT observado com o tratamento de BZDs no LCE e da neurobiologia da ansiedade, bem como, de outros distúrbios afetivos. 
Referências Bibliográficas* 
ANSELONI, V.C.Z.; MOTTA, V.; LIMA, G.; BRANDÃO, M.L. Behavioral and pharmacological validation of the elevated plus maze constructed with transparent walls. Brazilian Journal Medical and Biological Research, v.28, n.5, p.597-601, 1995.

AZMITIA, E.C.; SEGAL, M. An autoradiographic analysis of the differential ascending projections of the dorsal and median raphe nuclei in the rat. The Journal of Comparative Neurology, v.179, p.641-668, 1978.

BANNERMAN, D.M.; RAWLINS, J.N.P.; MCHUGH, S.B.; DEACON, R.M.J.; YEE, B.K.; BAST, T.; ZHANG, W.-N.; POTHUIZEN, H.H.J.; FELDON, J. Regional dissociations within the hippocampus-memory and anxiety. Neuroscience and Biobehavioral Reviews, v.28, p.273-283, 2004.

BARTUS, R.T.; DEAN, R.L.; PENTOCORVO, M.J.; FLICKER, C. The cholinergic hypothesis: a historical overview, current perspective and future directions. Annals of the New York Academy of Sciences, New York, v.444, p.332-358, 1985.

BERTOGLIO, L.J.; CAROBREZ, A.P. Previous maze experience required to increase open arms avoidance in rats submitted to the elevated plus-maze model of anxiety. Behavioural Brain Research, v.108, p.197-203, 2000.

BERTOGLIO, L.J.; CAROBREZ, A.P. Anxiolytic effects of ethanol and phenobarbital are abolished in test-experienced rats submitted to the elevated plus maze. Pharmacology Biochemistry \& Behavior, v.73, p.963-969, 2002a.

BERTOGLIO, L.J.; CAROBREZ, A.P. Behavioral profile of rats submitted to session1session 2 in the elevated plus-maze during diurnal/ nocturnal phases and under different illumination conditions. Behavioural Brain Research, v.132, p.135-143, 2002b.

BERTOGLIO, L.J.; CAROBREZ, A.P. Prior maze experience requered to alter midazolam effects in rats submitted to the elkevated plus-maze. Pharmacology Biochemistry \& Behavior, v.72, p.449-455, 2002c.

BERTOGLIO, L.J., CAROBREZ, A.P. Anxiolytic-like effects of NMDA/glycine-B receptor ligands are abolished during the elevated plus-maze trial 2 in rats. Psychopharmacology, v.170, p.335-342, 2003.

BERTOGLIO, L.J. Caracterização do efeito ansiolítico de drogas em ratos pré-expostos no labirinto em cruz elevado. 2004. 101f. Tese de Doutorado apresentada a Universidade Federal de Santa Catarina, Santa Catarina, 2004. 
BLANCHARD, D.C.; BLANCHARD, R.J. An ethoexperimental approach to the study of fear. The Psychological Record, v.37, p.305-316, 1987.

BLANCHARD, D.C.; BLANCHARD, R.J. Ethoexperimental approaches to the biology of emotion. Annual Review of Psychology, v.39, p.43-68, 1988.

BLISS, E.L.; AILION, J.; ZWANZIGER, J. Metabolism of norepinephrine, serotonin and dopamine in rat brain with stress. The Journal Pharmacology and Experimental Therapeutics, U.S.A., v.164, n.1, p.122-134, 1968.

BORELLI, K.G.; NOBRE, M.J.; BRANDÃO, M.L.; COIMBRA, N.C. Effects of acute and chronic fluoxetine and diazepam on freezing behavior induced by electrical stimulation of dorsolateral and lateral columns of the periaqueductal gray matter. Pharmacology Biochemistry \& Behavior, v.77, p.557-566, 2004.

BRANDÃO, M.L. Comportamento emocional. In: Psicofisiologia: As bases fisiológicas do comportamento. $2^{\mathrm{a}}$ ed. São Paulo: Editora Atheneu, 2001, cap.7, p.125-149.

BRANDÃO, M.L.; TRONCOSO, A.C.; SILVA, M.A.S.; HUSTON, J.P. The relevance of neuronal substrates of defense in the midbrain tectum to anxiety and stress: impirical and conceptual considerations. European Journal of Pharmacology, v.463, p.225-233, 2003.

CENCI, M.A.; KALEN, P.; MANDEL, R.J.; BJORKLUND, A. Regional differences in the regulation of dopamine and noradrenaline release in medial frontal cortex, nucleus accumbens and caudate-putamen: a microdialysis study in the rat. Brain Research, v.581, p.217-228, 1992.

CHARNEY, D.S.; DEUTCH, A.Y.; KRYSTAL, J.H.; SOUTHWICK, S.M.; DAVIS, M. Psychobiologic mechanisms of posttraumatic stress disorder. Archives of General Psychiatry, v.50, p.294-305, april 1993.

CHROUSOS, G.P.; GOLD, P.W. The concepts of stress and stress system disorders. Overview of physical and behavioral homeostasis. JAMA, v.267, p.1244-1252, 1992.

CLAUSTRE, Y.; RIVY, J.P.; DENNIS, T.; SCATTON, B. Pharmacological studies on stressinduced increase in frontal cortical dopamine metabolism in the rat. The Journal Pharmacology and Experimental Therapeutics, U.S.A., v.238, n.2, p.693-700, 1986. 
CRUZ, A.P.M.; FREI, F.; GRAEFF, F.G. Ethopharmacologycal analisys of rat behavior on the elevated plus-maze. Pharmacology Biochemistry \& Behavior, U.S.A., v.49, n.1, p.171176, 1994.

CRUZ-MORALES, S.E.; SANTOS, N.R., BRANDÃO, M.L. One-trial tolerance to midazolam is due to enhancement of fear and reduction of anxiolytic-sensitiv behaviors in the elevated plus-maze retest in the rat. Pharmacology Biochemistry \& Behavior, v.72, p.973978, 2002.

CUADRA, G., ZURITA, A.; LACERRA, C.; MOLINA, V. Chronic stress sensitizes frontal cortex dopamine release in response to a subsequent novel stressor: reversal by naloxone. Brain Research Bulletin, U.S.A., v.48, n.3, p.303-308, 1999.

CUADRA, G.; ZURITA, A.; MACEDO, C.E.; MOLINA, V.A.; BRANDÃO, M.L. Electrical stimulation of the midbrain tectum enhances dopamine release in the frontal cortex. Brain Research Bulletin, U.S.A., v.52, n.5, p.413-418, 2000.

DAL-CÓL, M.L.C; PEREIRA, O.L.; ROSA, V.P.; CALIXTO, A.V.; CAROBREZ, A.P.; FARIA, M.S. Lack of midazolam-induced anxiolysis in the plus-maze Trail 2 is dependent on the legth of Trial 1. Pharmacology Biochemistry \& Behavior, v.74, p.395-400, 2003.

DAVIS, M.; HITCHCOCK, J.M.; BOWERS, M.B.; BERRIDGE, C.W.; MELIA, K.R.; ROTH, R.H. Stress-induced activation of prefrontal cortex dopamine turnover: blockade by lesions of the amygdala. Brain Research, v.664, p.207-210, 1994.

DAWSON, G.R.; CRAWFORD, S.P.; STANHOPE, J.K.; INVERSE, S.D.; TRICKLEBANK, M.D. One-trial tolerance to the effects of chlordiazepoxide on the elevated plus-maze may be due to locomotor habituation, not repeated drug exposure. Psycopharmacology, v.113, p.570-572, 1994.

DEAKIN, J.F.W; GRAEFF, F.G. 5-HT and mechanisms of defence. Journal of Psychopharmacologycal, v.5, n.4, p.305-315, 1991.

DEAKIN, J.F.; GRAEFF, F.G.; GUIMARAES, F.S. 5-HT receptor subtypes and the modulation of aversion. In: MARSDEN, C.A.; HEAL, D.J. Central Serotonin Receptors and Psychotropic Drugs. London: Blackwell, 1992, p. 147-174.

DEUTCH, A.Y.; ROTH, R.H. The determinants of stress-induced activation of the prefrontal cortical dopamine system. Progress in Brain Research, v.85, p.367-402, 1990. 
DEUTSCH, J.A. The cholinergic synapse and the site of memory. Science, v.174, p.788-794, nov.1971.

DOMINGUEZ, R.; CRUZ-MORALES, S.E.; CARVALHO, M.C.; XAVIER, M.; BRANDÃO, M.L. Sex differences in serotonergic activity in dorsal and median raphe nucleus. Physiology \& Behaviour, v.80, p.203-10, 2003a.

DOMINGUEZ, R.; CRUZ-MORALES, S.E.; CARVALHO, M.C.; XAVIER, M.; BRANDÃO, M.L. Effect of steroid injection to newborn rats on serotonin activity in frontal córtex and raphe. Neuroreport. v.14, n.4, p.1-3, 2003b.

DRACTU, L.; LADER, M. Ansiedade: conceito, classificação e biologia. Uma interpretação contemporânea da literatura. Jornal Brasileiro de Psiquiatria, v.42, n.1, p.19-32, 1993.

DUNN, A. Stress-related changes in cerebral catecholamine and indoleamine metabolism: lack of effect of adrenalectomy and corticosterone. Journal of Neurochemistry, New York, v.51, n.2, p.406-412, 1988.

ESCARABAJAL, M.D.; TORRES, C.; FLAHERTY, C.F. The phenomenon of one-trial tolerance to the anxiolytic effect of chlordiazepoxide in the elevated plus-maze test is abolished by previous administration of chlordiazepoxide or buspirone. Life Sciences, v.73, p.1063-1074, 2003.

ESPEJO, E.F. Selective dopamine depletion within the medial prefrontal cortex induces anxiogenic-like effects in rats placed on the elevated plus maze. Brain Research, v.762, p.281-284, 1997.

FADDA, F.; ARGIOLAS, A.; MELIS, M.R.; TISSARI, A.H.; ONALI, P.L.; GESSA, G. Stress-induced increase in 3,4-dihydroxyphenylacetic acid (DOPAC) levels in the cerebral cortex and n. accumbens: reversal by diazepam. Life Sciences, U.S.A., v.23, p.2219-2224, 1978.

FANSELOW, M.S. The midbrain periaqueductal gray as a coordinator of action in response to fear and anxiety. In: DEPAULIS, A.; BANDLER, R. The Midbrain Periaqueductal Grey Matter: functional, Anatomical and Immunohistochemical Organization. New York: Plenum Publishing Corp, 1991, p.151-173.

FEENSTRA, M.G.P.; BOTTERBLOM, M.H.A.; VAN UUM, J.F.M. Novelty-induced increase in dopamine release in the rat prefrontal cortex in vivo: inhibition by diazepam. Neuroscience Letters, v.189, p.81-84, 1995. 
FILE, S.E. One-trial tolerance to the anxiolytic effect of chlordiazepoxide in the plus-maze. Psychopharmacology, v.100, p.281-282, 1990.

FILE, S.E.; MABBUTT, P. S.; HITCHCOTT, P. K. Characterization of phenomenon of "one-trial tolerance" to the anxiolytic effect of chlordiazepoxide in the elevated plus-maze. Psychopharmacology, v. 102, p.98-101, 1990.

FILE, S.E. Behavioural detection of anxiolytic action. In: ELLIOT, J.M.; HEAL, D.J.; MARSDEN, C.A. Experimental Approach to Anxiety and Depression. Chichester: John Wiley \& Sons Ltd, 1992, cap.3, p.25-44.

FILE, S.E. The interplay of learning and anxiety in the elevated plus-maze. Behavioural Brain Research, v.58, p.199-202, 1993.

FILE, S.E.; ZANGROSSI JÚNIOR, H. "One-trial tolerance” to the anxiolytic actions of benzodiazepines in the elevated plus-maze, or the development of a phobic state? Psychopharmacology, v.110, p.240-244, 1993.

FILE, S.E.; ZANGROSSI JÚNIOR, H.; VIANA, M.; GRAEFF, F.G. Trial 2 in the elevated plus-maze: a different form of fear? Psychopharmacology, v.111, p.491-494, 1993.

FINLAY, J.M.; ZIGMOND, M.J.; ABERCROMBIE, E.D. Increased dopamine and norepinephrine release in medial prefrontal cortex induced by acute and chronic stress: effects of diazepam. Neuroscience, Great Britain, v.64, n.3, p.619-628, 1995.

FRUSSA-FILHO, R.; RIBEIRO, R.A. One-trial tolerance to the effects chlordiazepoxide on the elevated plus-maze is not due to acquisition of a phobic avoidance of open arms during initial exposure. Life Sciences, v.71, p.519-525, 2002.

GELLER, I.; SEIFTER, J. The effects of meprobamate, barbitures, d-amphetamine and promazine on experimentally induced conflict in the rat. Psychopharmacology, v.1, p.482492, 1960.

GLAVIN, G.B. Stress and brain noradrenaline: a review. Neuroscience and Biobehavioral Reviews, v.9, n.2, p.233-243, 1985.

GOLDMAN-RAKIC, P.S.; LERANTH, C.; WILLIAMS, S.M.; MONS, N.; GEFFARD, M. Dopamine synaptic complex with pyramidal neurons in primate cerebral cortex. Proceedings of the National Academy of Science of America, v.86, n.22, p.9015-9019, nov.1989.

GOLDMAN-RAKIC, P. Cellular basis of working memory. Neuron, v.14, p.477-485, 1995. 
GOLDSTEIN, L.E.; RASMUSSON, A.M.; BUNNEY, B.S.; ROTH, R.H. The NMDA glycine site antagonist (+)-HA-966 selectively regulates conditioned stress-induced metabolic activation of the mesoprefrontal cortical dopamine but not serotonin systems: a behavioral, neuroendocrine, and neurochemical study in the rat. The Journal of Neuroscience, v.14, n.8, p.4937-4950, aug.1994.

GOLDSTEIN, L.E.; RASMUSSON, A.M.; BUNNEY, B.S.; ROTH, R.H. Role of the amygdala in the coordination of behavioral, neuroendocrine, and prefrontal cortical monoamine responses to psychological stress in the rat. The Journal of Neuroscience, v.16, n.15, p.4787-4798, aug.1996.

GONZALES, C.; CHESSELET, M.F. Amygdalonigral pathway: an anterograde study in the rat with phaseolus vulgaris leucoagglutinin (PHA-L). The Journal of Comparative Neurology, v.297, p.182-200, 1990.

GONZALEZ, L.E.; FILE, S.E. A five-minute experience in the elevated plus-maze alters the state of the benzodiazepine receptor in the dorsal raphe nucleus. The Journal of Neuroscience, v.17, n.4, p.1505-1511, feb.1997.

GOUDIE, A.J. Conditioned opponent processes in the development of tolerance to psychoactive drugs. Progress in Neuro-Psychopharmacology \& Biological Psychiatry, v.14, n.5, p.675-688, 1990.

GRAEFF, F.G. Ansiolíticos. In: Drogas Psicotrópicas e Seu Modo de Ação. $2^{\mathrm{a}}$ ed. São Paulo: EPU, 1989, cap. 5, p.61-83,.

GRAEFF, F.G. Serotonergic systems. Neuropsychiatry of the basal ganglia, v.20, n.4, p.723-739, dec.1997.

HJORTH, S.; SHARP, T. Effect of the 5-HT1A receptor agonist 8-OH-DPAT on the release of 5-HT in dorsal and medial raphe-innervated rat brain regions as measured by in vivo microdyalises. Life Sciences, U.S.A., v.48, p.1779-1786, 1991.

HOLMES, A.; RODGERS, R.J. Responses of Swiss-Webster mice to repeated plus-maze experience: further evidence for qualitative shift in emotional state? Pharmacology Biochemistry \& Behavior, v.60, n.2, p.473-488, 1998.

HOLMES, A.; RODGERS, R.J. Influence of spatial and temporal manipulations on the anxiolytic efficacy of clordiazepoxide in mice previously exposed to the elevated plus-maze. Neuroscience and Biobehavioral Reviews, v.23, p.971-980, 1999. 
HOLMES, A.; RODGERS, R.J. Prior exposure to the elevated plus-maze sensitizes mice to the acute behavioral effects of fluoxetine and phenelzine. European Journal of Pharmacology, v.459, p.221-230, 2003.

HUTCHINSON, M.A.; SMITH, P.F.; DARLINGTON, C.L. The behavioural and neuronal effects of the chronic adminitration of benzodizepine anxiolytic and hypnotic drugs. Progress in Neurobiology, Great Britain, v.49, p.73-97, 1996.

INOUE, T.; KOYAMA, T.; YAMASHITA, I. Effect of conditioned fear stress on serotonin metabolism in the rat brain. Pharmacology Biochemistry \& Behavior, U.S.A., v.44, p.371374, 1993.

INOUE, T.; TSUCHIYA, K.; KOYAMA, T. Effects of typical and atypical antipsychotic drugs on freezing behavior induced by conditioned far. Pharmacology Biochemistry \& Behavior, U.S.A., v.55, n.2, p.195-201, 1996.

JACOBS, B.L.; ABERCROMBIE, E.D.; FORNAL, C.A.; LEVINE, E.S.; MORILAK, D.A.; STAFFORD, I.L. Single-unit and physiological analyses of brain norepinephrine function in behaving animals. Progress in Brain Research, v.88, p.159-165, 1991.

KALANT, H. Research on tolerance: what can we learn from hitory? Alcoholism: Clinical and Experimental research, v.22, n.1, p.67-76, feb.1998.

KANEYUKI, H.; YOKOO, H.; TSUDA, A.; YOSHIDA, M.; MIZUKI, Y.; YAMADA, M.; TANAKA, M. Psychological stress increases dopamine turnover selectively in mesoprefrontal dopamine neurons of rats: reversal by diazepam. Brain Research, v.557, p.154-161, 1991.

KERDELHUÉ, B.; BOJDA, F.; LESIUR, P.; PASQUALINI, C.; EL ABED, A.; LENOIR, V., DOUILLET, P.; CHUIEH, M.C.; PALKOVITS, M. Median eminence dopamine and serotonin neuronal activity. Temporal relationship to preovulatory prolactin and luteinizing hormones surges. Neuroendocrinology, v.49, p.176-180, 1989.

KIRBY, L.C.; RICE, K.C.; VALENTINO, R.J. Effects of corticotropin-releasing factor on neuronal activity in the serotoninergic dorsal raphe nucleus. Neuropsycopharmacology, New York, v.22, n.2, p.148-162, 2000.

KRETTEK, J.E.; PRICE, J.L. Projections from the amygdaloid complex to the cerebral cortex and thalamus in the rat and cat. The Journal of Comparative Neurology, v.172, p.687-722, 1977. 
LÊ, A.D.; POULOS C.X.; CAPPEL, H. Conditioned tolerance to the hypothermia effect of ethyl alcohol. Science, v.206, p.1109-1110, nov.1979.

LEDOUX, J. Brain mechanisms of emotion and emotional learning. Current Opinion of Neurobiology, v.2, n.2, p.191-197, apr.1992.

LISTER, R.G. The use of a plus-maze to measure enxiety in the mouse. Psychopharmacology, v.92, p.180-185, 1987.

LISTER, R.G. Ethologically based animal models of anxiety disorders. Pharmacology \& Therapeutics, Great Britain, v.46, p.321-340, 1990.

MAAS, J.W.; DEKIRMENJIAN, H.; FAWCETT, J. Catecholamine metabolism, depression and stress. Nature, v.230, p.330-331, april 1971.

MAEDA, H.; MOGENSON, G.J. Electrophysiological responses of neurons of the ventral tegmental area to electrical stimulation of amygdala and lateral septum. Neuroscience, Great Britain, v.6, n.3, p.367-376, 1981.

MCDONALD, A.J. Organization of amygdaloid projections to the prefrontal cortex and associated striatum in the rat. Neuroscience, Great Britain, v.44, n.1, p.1-14, 1991.

MCNAUGHTON, N.; GRAY, J.A. Anxiolytic action on the behavioural inhibition system implies multiple types of arousal contribute to anxiety. Journal of Affective Disorders, v.61, p.161-176, 2000.

MILLAN, M.J. The neurobiology and control of anxious states. Progress in Neurobiology, v.70, p.83-244, 2003.

MILLER, N.S.; GOLD, M.S. Benzodiazepines: Tolerance, dependence, abuse, and addiction. Journal of Psychoative Drugs, v.22, n.1, p.23-33, 1990.

MOGENSON, G.; JONES, D.; YIM, C. From motivation to action: functional interface between the limbic system and the motor system. Progress in Neurobiology, v.14, p.69-97, 1980.

MONGEAU, R.; BLIER, P.; DE MONTIGNY, C. The serotoninergic and noradrenergic systems of the hippocampus: their interactions and the effects of antidepressant treatments. Brain Research Rewies, v.23, p.145-195, 1997. 
MONTGOMERY, K.C. The relationship between fear induced by novel stimulation and exploratory behavior. Journal of Comparative Physiology and Psychology, v.48, p. 254260, 1955.

MOORE, R.Y.; HALARIS, A.E.; JONES, B.E. Serotonin neurons of the midbrain raphe: ascending projections. The Journal of Comparative Neurology, v.180, p.417-438, 1978.

MORRISON, C.F.; STEPHENSON, J.A. Drug effects on a measure of unconditioned avoidance in the rat. Psychopharmacology, v.18, n.2, p.133-143, 1970.

MORROW, B.A.; ELSWORTH, J.D.; RASMUSSON, A.M.; ROTH, R.H. The role of mesoprefrontal dopamine neurons in the acquisition and expression of conditioned fear in the rat. Neuroscience, Great Britain, v.92, n.2, p.553-564, 1999.

NAKANE, H.; SHIMIZU, N.; HORI, T. Stress-induced norepinephrine release in the rat prefrontal cortex measured by microdialysis. American Journal of Physiology, v.267, p.R1559-R1566, 1994.

NUTT, D.J. The pharmacology of human anxiety. Pharmacology \& Therapeutics, Great Britain, v.47, p.233-266, 1990.

NUTT, D.J. Anxiety and its therapy: today and tomorrow. In: Briley, M.; File, S.E. New Concepts in Anxiety. London: Macmillan, 1991, p.1-12.

PELLOW, S.; CHOPIN, P.; FILE, S.E.; BRILEY, M. Validation of open: closed arm entries in an elevated plus-maze as a measure of anxiety in the rat. Journal of Neuroscience Methods, v.14, p.149-167, 1985.

PENNARTZ, C.; GROENEWEGEN, H.; LOPEZ DA SILVA, F.H. The nucleus accumbens as a complex of functionally distinct neuronal ensembles: an integration of behavioural, electrophysiological and anatomical data. Progress in Neurobiology, v.42, p.719-761, 1994.

PEREIRA, J.K.D.; VIEIRA, R.J.; KONISHI, C.T.; RIBEIRO, R.A.; FRUSSA-FEILHO, R. The phenomenon of "one-trial tolerance" to the anxiolytic effect of chlordiazepoxide in the elevated plus-maze is abolished by the introduction of a motivational conflict situation. Life Sciences, U.S.A., v.65, n.10, p.101-107, 1999.

POST, R.M. Transduction of psychosocial stress into the neurobiology of recurrent affective disorder. American Journal of Physiology, v.149, p.999-1010, 1992. 
PRATT, J.A. The neuroanatomical basis of anxiety. Pharmacology \& Therapeutics, Great Britain, v.55, p.149-181, 1992.

PRICE, M.E.; CURTIS, A.L.; KIRBY, L.G.; VALENTINO, R.J.; LUCKI, I. Effects corticotrofin-releasing factor on brain serotoninergic activity. Neuropsycopharmacology, New York, v.18, n.6, p.492-502, 1998.

RALL, T.W. Hypnotics and sedatives; ethanol. In: RALL, T.W; NIES, A.S.; TAYLOR. Goodman and Gilman's The pharmacological basis of therapeutics. New York: Pergamon Press, 1991, p.345-382.

REINHARD, J.F.; BANNON, M.J.; ROTH, R.H. Activation by stress of dopamine synthesis and metabolism in the prefrontal cortex: antagonism by diazepam. Naunyn Schmiedeberg's Archives of Pharmacology, v.318, p.374-377, 1982.

RODGERS, R.J.; LEE, C.; SHEPHERD, J.K. Effects of diazepam on behavioural and antinociceptive responses to the elevated plus-maze in male mice depend upon treatment regimen and proir maze experience. Psychopharmacology, v.106, p.102-110, 1992.

RODGERS, R.J.; SHEPHERD, J.K. Influence of prior maze experience on behaviour and responses to diazepam in the elevated plus-maze and light/dark tests of anxiety in mice. Psychopharmacology, v.113, p.237-242, 1993.

ROTH, R.H.; TAM, S-Y.; IDA, Y.; YANG, J.X.; DEUTCH, A.Y. Stress and mesocorticolimbic dopamine systems. Annals of the New York Academy of Sciences, v.537, p.138-147, 1988.

SAJDKY, T.J.; KATNER, J.S.; SHEKHAR, A. Monoamines in the dorsomedial hypothalamus of rats following exposure to different tests of "anxiety". Progress in NeuroPsychopharmacology \& Biological Psychiatry, U.S.A., v.21, p.193-209, 1997.

SANDFORD, J.J.; ARGYROPOULOS, S. V.; NUTT, D. J. The psychobioology of anxiolytic drugs. Part 1: basic neurobiology. Pharmacology \& Therapeutics, v.88, p.197-212, 2000.

SESACK, S.R.; PICKEL, V.M. Prefrontal cortical efferents in the rat synapse on unlabeled neuronal targets of catecholamine terminal in the nucleus accumbens septi and on dopamine neurons in the ventral tegmental area. The Journal of Comparative Neurology, v.320, p.145-160, 1992. 
SIEGEL, S. Pavlovian condioting and ethanol tolerance. In: LINDROS, K.O.; YLIKAHRI, R.; KIIANMAA, A. Advances in biomedical alcohol research. Oxford: Pergamon Press, 1987, p.25-33.

SIEGEL, S.; LARSON, S.J. Disruption of tolerance to the ataxic effect of ethanol by an axtraneous stimulus. Pharmacology Biochemistry \& Behavior, U.S.A., v.55, n.1, p.125130, 1996.

SIEGEL, S.; BAPTISTA, M.A.S.; KIM, J.A.; McDONALD, R.V.; WEISE-KELLY, L. Pavlovian psychopharmacology: The associative basis of tolerance. Experimental and Clinical Psychopharmacology, v.8, n.3, p.276-293, 2000.

SOUTHWICK, S.M.; KRYSTAL, J.H.; MORGAN, A.; JOHNSON, D.; NAGY, L.M.; NICOLAOU, A.; HENINGER, G.R.; CHARNEY, D.S. Abnormal noradrenergic function in posttraumatic stress disorder. Archives of General Psychiatry, v.50, p.266-274, april 1993.

SWEENEY, D.R.; MAAS, J.W.; HENINGER, G.R. State anxiety, physical activity, and urinary 3-methoxy-4-hydroxyphenethylene glycol excretion. Archives of General Psychiatry, v.35, p.1418-1423, dec.1978.

TANAKA, M.; TSUDA, A.; YOKOO, H.; YOSHIDA, M., IDA, Y.; NISHIMURA, H. Involvement of the brain noradrenaline system in emotional changes caused by stress in rats. Annals of the New York Academy of Sciences, v.597, p.159-174, 1990.

THIERRY, A.M.; FEKETE, M.; GLOWIINSKI, J. Effects of stress on the metabolism of noradrenaline, dopamine and serotonin (5-HT) in the central nervous system of the rat. II. Modifications of serotonin metabolism. European Journal of Pharmacology, Amsterdam, v.4, n.4, p.384-389, 1968.

THIERRY, A.M.; TASSIN, J.P.; BLANC, G.; GLOWINSKI, J. Selective activation of the mesocortical DA system by stress. Nature, v.263, p.242-243, 1976.

TREIT, D. Animal models for the study of anti-anxiety agents: a review. Neuroscience \& Biobehavioral Reviews, U.S.A., v.9, n.2, p.203-222, 1985.

TREIT, D.; MENARD, J.; ROYAN, C. Anxiogenic stimuli in the elevated plus-maze. Pharmacology Biochemistry \& Behavior, U.S.A., v.44, p.463-469, 1993. 
VALENTINO, R.J.; LJOUTERMAN, L.; VAN BOCKSTACLE, E.J. Evidence for regional heterogeneity in corticotropin-releasing factor interactions in the dorsal raphe nucleus. The Journal of Comparative Neurology, v.435, n.4, p.450-463, jul.2001.

VINCENT, S.L.; KHAN, Y.; BENES, F.M. Cellular distribution of dopamine D1 and D2 receptors in rat medial prefrontal cortex. The Journal of Neuroscience, v.13, n.6, p.25512564, jun.1993.

VOGEL, J.R.; BEER, B.; CLODY, D.E. A simply and reliable conflit of procedure for testing anti-anxiety agents. Psychopharmacology, v.21, p.1-7, 1971.

WALLACE, D.M.; MAGNUSON, D.J.; GRAY, T.S. Organization of amygdaloid projections to brainstem dopaminergic, noradrenergic and adrenergic cell groups in the rat. Brain Research Bulletin, U.S.A., v.28, p.447-454, 1992.

WEISS, J.M.; GOODMAN, P.A.; LOSITO, B.G.; CORRIGAN, S.; CHARRY, J.M.; BAILEY, W.H. Behavioral depression produced by an uncontrollable stressor: relationship to norepinephrine, dopamine and serotonin levels in various regions of the rat brain. Brain Research Reviews, v.3, p.167-205, 1981.

WOODS, S.C.; RAMSAY, D.S. Pavlovian influences over food and drug intake. Behavioural Brain Research, v.110, p.175-182, 2000.

\footnotetext{
* De acordo com:
}

Manual de Referências e Citações bibliográficas do Sistema Integrado de Biblioteca da USP, baseado nas normas da ABNT (Associação Brasileira de Normas Técnicas). 
Apêndices 
Tabela 1: Valores referentes às medidas de comportamentos tradicionais após a segunda exposição no LCE. Valores representados em média \pm EPM. TTO: tratamento, BA: braços abertos, BF: braços fechados, $M$-S: midazolam e salina, $M-M$ : midazolam e midazolam. $\mathrm{N}=8$ animais em cada grupo.

\begin{tabular}{|l|c|c|c|c|}
\hline TTO & Entradas nos BA & Entradas nos BF & $\begin{array}{c}\text { \% de entradas } \\
\text { nos BA }\end{array}$ & $\begin{array}{c}\text { \% de tempo nos } \\
\text { BF }\end{array}$ \\
\hline M-S & $1,55 \pm 0,47$ & $8,09 \pm 1,00$ & $12,87 \pm 3,00$ & $3,60 \pm 1,21$ \\
\hline M-M & $1,00 \pm 0,40$ & $5,00 \pm 0,88$ & $9,96 \pm 3,58$ & $2,50 \pm 0,96$ \\
\hline
\end{tabular}

Tabela 2: Valores referentes ao comportamento exploratório de ratos submetidos a segunda exposição ao LCE. EXP: exploração da extremidade aberta; RAS: rastejamento; EST: esticamento; IMOB: imobilidade; ESP: espreitamento; LIM: auto-limpeza; MERG: mergulho da cabeça; LEV: levantamento e ESQ: esquadrinhamento. Os valores representam as médias \pm EPM. M-S: midazolam e salina; M-M: midazolam e midazolam. $\mathrm{N}=11$ animais em cada grupo.

\begin{tabular}{|l|c|c|}
\hline & M-S & M-M \\
\hline EXP & $1,00 \pm 0,47$ & $0,73 \pm 0,27$ \\
\hline RAS & $1,55 \pm 0,37$ & $1,00 \pm 0,47$ \\
\hline EST & $2,55 \pm 0,49$ & $2,00 \pm 0,47$ \\
\hline IMOB & $0,64 \pm 0,31$ & $2,64 \pm 1,01$ \\
\hline ESP & $2,73 \pm 0,70$ & $1,55 \pm 0,53$ \\
\hline LIM & $4,91 \pm 1,04$ & $3,64 \pm 0,74$ \\
\hline MERG & $1,27 \pm 0,36$ & $1,36 \pm 0,43$ \\
\hline LEV & $13,36 \pm 1,21$ & $8,64 \pm 1,26$ \\
\hline ESQ & $17,55 \pm 0,91$ & $13,91 \pm 1,58$ \\
\hline
\end{tabular}




\begin{tabular}{|c|c|c|c|c|c|c|}
\hline$\stackrel{3}{\stackrel{3}{N}}$ & $\stackrel{\infty}{\stackrel{\infty}{N}}$ & $\stackrel{3}{\stackrel{3}{\Theta}}$ & $\stackrel{\infty}{\stackrel{\theta}{\ominus}}$ & $\Omega$ & & \\
\hline 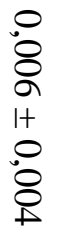 & $\begin{array}{l}0 \\
\stackrel{0}{0} \\
1+ \\
\circ \\
\circ \\
0\end{array}$ & 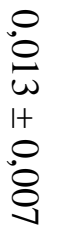 & 0 & $\begin{array}{l}\stackrel{0}{\circ} \\
\stackrel{尸}{1} \\
1+ \\
\circ \\
\circ\end{array}$ & $\sum_{D}$ & \multirow{2}{*}{$\underset{7}{7}$} \\
\hline $\begin{array}{l}0 \\
\text { O } \\
\text { O } \\
1+ \\
0 \\
0 \\
\sigma\end{array}$ & $\begin{array}{l}0 \\
0 \\
0 \\
0 \\
1+ \\
0 \\
0 \\
0\end{array}$ & $\begin{array}{l}\text { O } \\
\stackrel{N}{N} \\
1+ \\
0 \\
\stackrel{N}{N}\end{array}$ & 0 & $\begin{array}{l}0 \\
\stackrel{0}{\sigma} \\
1+ \\
0 \\
\stackrel{\bullet}{\bullet}\end{array}$ & 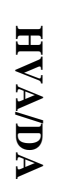 & \\
\hline $\begin{array}{l}\circ \\
\stackrel{0}{N} \\
\text { H+ } \\
\circ \\
\stackrel{0}{O}\end{array}$ & 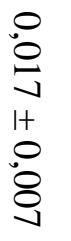 & $\begin{array}{l}0 \\
0 \\
\omega \\
1+ \\
0 \\
0 \\
0\end{array}$ & $\begin{array}{l}0 \\
0 \\
0 \\
0 \\
1+ \\
\circ \\
0 \\
0\end{array}$ & $\begin{array}{l}\circ \\
8 \\
8 \\
8 \\
1+ \\
\circ \\
\stackrel{8}{8} \\
6\end{array}$ & $\sum_{D}^{\top}$ & \multirow{2}{*}{$\frac{8}{3}$} \\
\hline $\begin{array}{l}0 \\
0 \\
\omega \\
1+ \\
\circ \\
\stackrel{0}{O}\end{array}$ & $\begin{array}{l}\circ \\
\stackrel{0}{0} \\
\omega \\
1+ \\
\circ \\
\circ\end{array}$ & $\begin{array}{l}0 \\
0 \\
\omega \\
1+ \\
0 \\
\circ \\
\circ\end{array}$ & $\begin{array}{l}\circ \\
\circ \\
\circ \\
1+ \\
\circ \\
\circ \\
0\end{array}$ & $\begin{array}{l}0 \\
8 \\
8 \\
1 \\
1+ \\
0 \\
0 \\
8 \\
8\end{array}$ & $\sum_{D}^{i}$ & \\
\hline
\end{tabular}

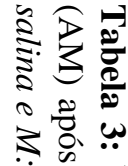

३. ำ

응.

용 क

今 次 110 苑

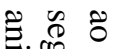

ㅋ.

期

ชิํํㅇำ

응

용

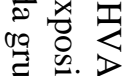

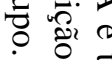

욤

กิ

प⿴囗十丁

o

נ艹

官 用

萣

䨌

䒿

के

寻

궁

的要

四

ก

อ ำ

节

응

की 


\begin{tabular}{|c|c|c|c|c|c|c|}
\hline$\stackrel{3}{\stackrel{3}{N}}$ & $\stackrel{\infty}{\stackrel{\sim}{N}}$ & $\stackrel{3}{\stackrel{3}{\Theta}}$ & $\stackrel{\infty}{\text { 舄 }}$ & ת & & \\
\hline 0 & $\begin{array}{l}0 \\
\stackrel{0}{8} \\
\circ \\
1+ \\
\circ \\
\circ \\
\varnothing\end{array}$ & 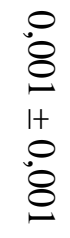 & $\begin{array}{l}\circ \\
\circ \\
\circ \\
\circ \\
1+ \\
\circ \\
\circ \\
\circ\end{array}$ & 0 & $\sum_{D}$ & \multirow{2}{*}{$\boldsymbol{\nabla}$} \\
\hline 0 & $\begin{array}{l}0 \\
8 \\
8 \\
1+ \\
\circ \\
8 \\
8\end{array}$ & $\begin{array}{l}0 \\
8 \\
8 \\
+ \\
1+ \\
0 \\
0 \\
8 \\
8\end{array}$ & $\begin{array}{l}0 \\
\text { O } \\
\text { N } \\
1+ \\
\circ \\
\text { O } \\
\text { N }\end{array}$ & 0 & $\sum_{D}^{i}$ & \\
\hline 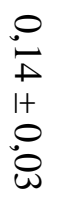 & 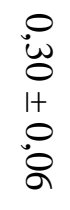 & $\begin{array}{l}\circ \\
\stackrel{0}{N} \\
1+ \\
\text { 1 } \\
\stackrel{0}{0}\end{array}$ & $\begin{array}{l}\circ \\
0 \\
\dot{1} \\
1+ \\
\circ \\
\circ \\
0\end{array}$ & 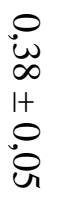 & $\sum_{D}$ & \multirow{2}{*}{ 敠 } \\
\hline 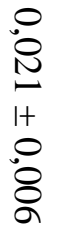 & 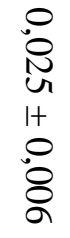 & $\begin{array}{l}\circ \\
\circ \\
\circ \\
1+ \\
\circ \\
\circ\end{array}$ & $\begin{array}{l}0 \\
\circ \\
\circ \\
1+ \\
\circ \\
\circ \\
\circ\end{array}$ & 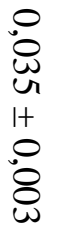 & $\underset{D}{\stackrel{T}{2}}$ & \\
\hline
\end{tabular}

望烦 象苛

$\because$

ํ. ำ

동. 궁

ㅇ.

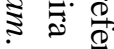

乙互

11 筮

芑. \%

宊

.

के वृ

ใิ

응

วิ

骂品

०ิ

항

เ命

กิ⿴囗十丁

일

ปิ

คิ

क

ซ

틀.

罗

क 面

ヨ

芯

$1+0$

벙 응

当

ก $\frac{2}{8}$

ริ ล

志

$\frac{9}{8}$ 
Tabela 5: Valores referentes às medidas neuroquímicas e taxa de renovação no córtex pré-frontal (CPfr) após a segunda exposição no LCE. Os valores representam as médias \pm EPM. M-S: midazolam e salina; $M$-M: midazolam e midazolam. $\mathrm{N}=8$ animais para cada grupo.

\begin{tabular}{|l|c|c|}
\hline \multicolumn{2}{|c|}{ CPfr } \\
\hline & M-S & M-M \\
\hline 5-HT & $0,74 \pm 0,12$ & $1,01 \pm 0,23$ \\
\hline 5-HIAA & $0,22 \pm 0,02$ & $0,24 \pm 0,04$ \\
\hline DA & $0,09 \pm 0,03$ & $0,07 \pm 0,03$ \\
\hline DOPAC & $0,010 \pm 0,004$ & $0,03 \pm 0,01$ \\
\hline NA & $0,49 \pm 0,12$ & $0,51 \pm 0,13$ \\
\hline 5-HIAA/5-HT & $0,32 \pm 0,02$ & $0,26 \pm 0,02$ \\
\hline DOPAC/DA & $0,05 \pm 0,02$ & $1,20 \pm 0,90$ \\
\hline
\end{tabular}


Tabela 6: Valores referentes às medidas neuroquímicas e taxa de renovação na amígdala (AM) após a segunda exposição no LCE. Os valores representam as médias \pm EPM. M-S: midazolam e salina; M-M: midazolam e midazolam. $\mathrm{N}=8$ animais para cada grupo.

\begin{tabular}{|l|c|c|}
\hline \multicolumn{2}{|c|}{ AM } \\
\hline 5-HT & $1,65 \pm 0,62$ & M-M \\
\hline 5-HIAA & $0,61 \pm 0,21$ & $0,89 \pm 0,32$ \\
\hline DA & $1,05 \pm 0,16$ & $1,11 \pm 0,29$ \\
\hline DOPAC & $0,09 \pm 0,03$ & $0,10 \pm 0,04$ \\
\hline NA & $0,89 \pm 0,14$ & $1,08 \pm 0,20$ \\
\hline 5-HIAA/5-HT & $0,39 \pm 0,03$ & $0,35 \pm 0,02$ \\
\hline DOPAC/DA & $0,07 \pm 0,01$ & $0,07 \pm 0,01$ \\
\hline
\end{tabular}


Tabela 7: Valores referentes às medidas neuroquímicas e taxa de renovação no hipocampo (HP) após a segunda exposição no LCE. Os valores representam as médias \pm EPM. M-S: midazolam e salina; M-M: midazolam e midazolam. $\mathrm{N}=8$ animais para cada grupo.

\begin{tabular}{|l|c|c|}
\hline \multicolumn{2}{|c|}{ HP } & M-S \\
\hline 5-HT & $0,49 \pm 0,03$ & $0,83 \pm 0,18$ \\
\hline 5-HIAA & $0,28 \pm 0,02$ & $0,43 \pm 0,10$ \\
\hline DA & $0,10 \pm 0,05$ & $0,23 \pm 0,11$ \\
\hline DOPAC & $0,010 \pm 0,004$ & $0,009 \pm 0,005$ \\
\hline NA & $0,62 \pm 0,05$ & $0,81 \pm 0,11$ \\
\hline 5-HIAA/5-HT & $0,58 \pm 0,03$ & $0,51 \pm 0,02$ \\
\hline DOPAC/DA & $0,09 \pm 0,06$ & $0,02 \pm 0,01$ \\
\hline
\end{tabular}


Tabela 8: Valores referentes às medidas neuroquímicas e taxa de renovação no núcleo accumbens (NAc) após a segunda exposição no LCE. Os valores representam as médias \pm EPM. M-S: midazolam e salina; M-M: midazolam e midazolam. $\mathrm{N}=8$ animais para cada grupo.

\begin{tabular}{|l|c|c|}
\hline \multicolumn{2}{|c|}{ NAc } \\
\hline 5-HT & $2,96 \pm 0,49$ & M-M \\
\hline 5-HIAA & $1,03 \pm 0,15$ & $0,44 \pm 0,04$ \\
\hline DA & $8,91 \pm 1,86$ & $9,24 \pm 1,15$ \\
\hline DOPAC & $0,92 \pm 0,19$ & $0,88 \pm 0,12$ \\
\hline NA & $0,70 \pm 0,18$ & $0,82 \pm 0,16$ \\
\hline 5-HIAA/5-HT & $0,35 \pm 0,01$ & $0,38 \pm 0,05$ \\
\hline DOPAC/DA & $0,105 \pm 0,005$ & $0,10 \pm 0,01$ \\
\hline
\end{tabular}


Tabela 9: Valores referentes às medidas neuroquímicas e taxa de renovação no córtex pré-frontal (CPfr) e amígdala (AM) após o tratamento com midazolam. Os valores representam as médias \pm EPM. $\mathrm{N}=8$ animais para cada grupo.

\begin{tabular}{|l|c|c|}
\hline & CPfr & AM \\
\hline 5-HT & $1,43 \pm 0,14$ & $5,74 \pm 0,40$ \\
\hline 5-HIAA & $0,35 \pm 0,03$ & $1,81 \pm 0,13$ \\
\hline DA & $0,088 \pm 0,006$ & $2,02 \pm 0,34$ \\
\hline DOPAC & $0,003 \pm 0,002$ & $0,33 \pm 0,18$ \\
\hline NA & $0,63 \pm 0,07$ & $1,53 \pm 0,02$ \\
\hline 5-HIAA/5-HT & $0,25 \pm 0,01$ & $0,32 \pm 0,01$ \\
\hline DOPAC/DA & $0,04 \pm 0,02$ & $0,14 \pm 0,06$ \\
\hline HVA/DA & 0 & 0 \\
\hline
\end{tabular}


Tabela 10: Valores referentes às medidas neuroquímicas e taxa de renovação no hipocampo (HP) e núcleo accumbens (NAc) após o tratamento com midazolam. Os valores representam as médias \pm EPM. $\mathrm{N}=8$ animais para cada grupo.

\begin{tabular}{|l|c|c|}
\hline & HP & NAc \\
\hline 5-HT & $1,84 \pm 0,30$ & $4,48 \pm 0,43$ \\
\hline 5-HIAA & $0,83 \pm 0,05$ & $1,33 \pm 0,14$ \\
\hline DA & $0,07 \pm 0,04$ & $11,23 \pm 1,33$ \\
\hline DOPAC & 0 & $1,60 \pm 0,24$ \\
\hline NA & $1,34 \pm 0,15$ & $0,30 \pm 0,01$ \\
\hline 5-HIAA/5-HT & $0,53 \pm 0,08$ & $0,079 \pm 0,004$ \\
\hline DOPAC/DA & 0 & $0,038 \pm 0,002$ \\
\hline HVA/DA & 0 & \\
\hline
\end{tabular}

